\title{
Copper(II) Complexes of Cyclams Containing Nitrophenyl Substituents: Push-pull Behaviour and Scorpionate Coordination of the Nitro Group
}

\author{
Massimo Boiocchi, ${ }^{\dagger}$ Carlo Ciarrocchi, ${ }^{\dagger}$ Luigi Fabbrizzi, ${ }^{* \dagger}{ }^{\dagger}$ Maurizio Licchelli, ${ }^{\dagger}$ Antonio Poggi, ${ }^{\dagger}$ \\ Miguel Vázquez López ${ }^{\S}$ \\ $†$ Centro Grandi Strumenti, Università di Pavia, via Bassi 21, 27100 Pavia, Italy \\ $\$$ Dipartimento di Chimica, Università di Pavia, via Taramelli 12, 27100 Pavia, Italy \\ $\S$ Departamento de Química Orgánica, Universidade de Santiago de Compostela, 15782 Santiago de \\ Compostela, Spain
}

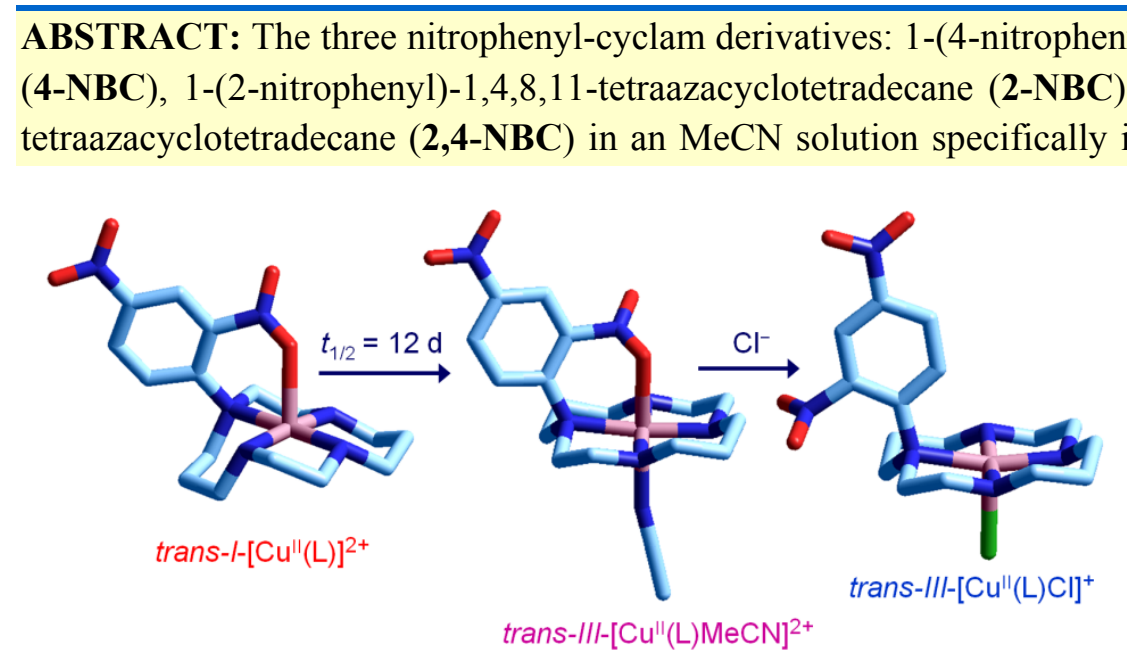
while the metallocyclam system exhibits a trans-I configuration. In an $\mathrm{MeCN}$ solution the red trans- $I-\left[\mathrm{Cu}^{\mathrm{II}}(\mathbf{2}-\mathbf{N B C})\right]^{2+}$ and trans- $I-\left[\mathrm{Cu}^{\mathrm{II}}(\mathbf{2}, \mathbf{4}-\mathbf{N B C})\right]^{2+}$ scorpionate complexes slowly convert into the violet trans-III scorpionate complexes. Kinetic aspects of the trans-I-to-trans-III configurational rearrangement have been investigated in detail for the $\left[\mathrm{Cu}^{\mathrm{II}}(\mathbf{2}, \mathbf{4 - N B C})\right]^{2+}$ system. In particular, the conversion is spectacularly accelerated by catalytic amounts of $\mathrm{Cl}^{-}, \mathrm{NCO}^{-}$and $\mathrm{F}^{-}$. While for $\mathrm{Cl}^{-}$and $\mathrm{NCO}^{-}$the effect can be associated to the capability of the anion to stabilize through coordination a possible dissociative intermediate, the amazingly powerful effect of $\mathrm{F}^{-}$has to be related to the preliminary deprotonation of one $\mathrm{N}-\mathrm{H}$ fragment of the macrocycle, driven by the formation of the $\mathrm{HF}_{2}^{-}$ion. Most of the metal complex species studied in solution have been isolated in a crystalline form and their molecular structure has been elucidated through X-ray diffraction studies. This study documents the first examples of effective metal coordination by the nitro group.

\section{Introduction}

$N, N$-dimethyl(4-nitro)-aniline (1a, DMNA) is a classical push-pull system D-Ph-A, in which a the dimethylamino donor group D and the nitro acceptor group A are connected via the $\pi$-conjugated system of a phenyl ring $(\mathrm{Ph})$. The molecule exhibits a pronounced polar character, with $\mu_{0}=5.92 \mathrm{D}$. On light absorption, the system is excited to the state $\mathbf{1 b}$, which involves a substantial transfer of electron density from $\mathrm{D}$ to $\mathrm{A}$, as depicted in Scheme 1. 


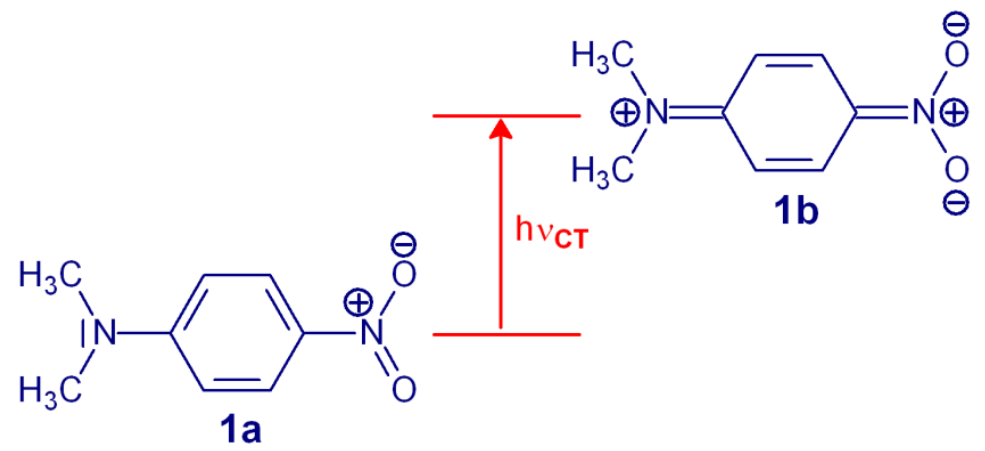

Scheme 1. Charge transfer (CT) optical transition in $N, N$-dimethyl(4-nitro)-aniline (DMNA).

The optical transition is therefore defined charge transfer (CT) transition, characterized by an intense absorption band in the visible region $\left(\lambda_{\max }=390 \mathrm{~nm}, \varepsilon=20600 \mathrm{M}^{-1} \mathrm{~cm}^{-1}\right.$, EPA, 77K). The highly polar nature of the excited state accounts for the distinctive solvatochromic behaviour. The more polar the solvent, the more pronounced the red shift of the absorption band.



2

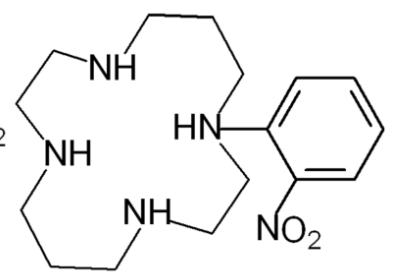

3

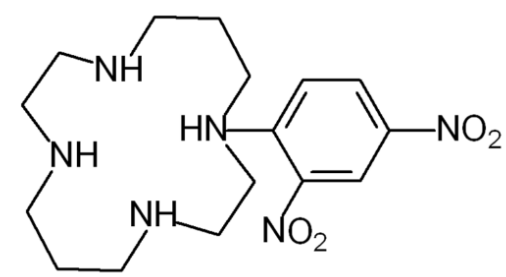

4

We had previously appended the DMNA subunit to the framework of cyclam and we had observed that the resulting macrocycle 2 was able to incorporate irreversibly and selectively the copper(II) ion. ${ }^{1}$ Coordination of $\mathrm{Cu}^{2+}$ to the anilino nitrogen atom of $\mathbf{2}$ makes the intensity of the dipole decrease. As a consequence, the CT band is remarkably blue-shifted (from 386 t0 $266 \mathrm{~nm}$ ) and, on $\mathrm{Cu}^{\mathrm{II}}$ addition, under diluted conditions $\left(<10^{-4} \mathrm{M}\right)$, the yellow-orange solution of 2 turns colourless. Macrocyle 2 can be therefore considered an exclusive optical dosimeter of $\mathrm{Cu}^{\text {II }}{ }^{2}$ Moreover, structural studies on the $\left[\mathrm{Cu}^{\mathrm{II}}(2)\right]\left(\mathrm{ClO}_{4}\right)_{2}$ complex showed that the $\mathrm{Cu}^{2+}$ ion is fully encircled by the macrocycle according to a square geometry. ${ }^{1}$

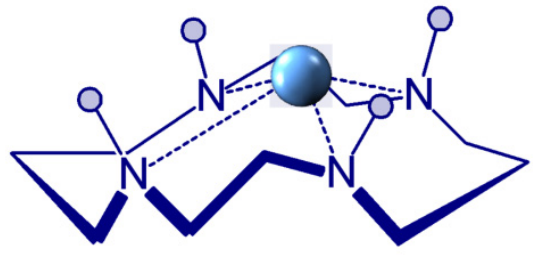

trans-I $(R, S, R, S)$



trans-III $(R, R, S, S)$

Scheme 2. Trans-I and trans-III configurational isomers of metal cyclam complexes.

Quite interestingly, the macrocycle adopts the $R, S, R, S$ configuration (diastereoisomer trans- $I$, see Scheme 2), rather unusual for metal complexes of mono-substituted cyclam derivatives and typically observed with metal complexes of $N, N^{\prime}, N$,',$N$, ',-tetrasubstituted cyclams. ${ }^{3}$ On the other hand, unsubstituted or mono $N$-substituted cyclam complexes usually adopt an $R, R, S, S$ configuration (trans-III) (see Scheme 2). ${ }^{4}$ 
We wish now to extend the study to the copper(II) complexes of cyclam derivatives with a 2-nitrophenyl (3) and with a 2,4-dinitrophenyl substituent (4). This could allow us to evaluate (i) how $\mathrm{Cu}^{\text {II }}$ coordination modifies the properties of the push-pull chromophore and (ii) if the 2-nitro group can bind the metal center from the top, according to a scorpionate mode. Factors affecting the coordination of the nitro group have been elucidated thanks to the determination of the crystal and molecular structures of seven complex salts of macrocycles $\mathbf{2 , 3}$ and $\mathbf{4}$. They are the only structures available for metal complexes of cyclam derivatives with a nitrobenzyl substituent directly linked to a nitrogen atom, along with the precursor complex described in ref. (1). Noticeably, the $-\mathrm{NO}_{2}$ group had been observed to coordinate the $\mathrm{Cu}^{\mathrm{II}}$ ion only in the nitronate form, in a macrocycle in which the 2-nitrophenyl fragment was appended through an ethylenic chain to a nitrogen atom of cyclam. ${ }^{5}$

\section{RESULTS AND DISCUSSION}

Macrocycles 2, 3 and 4 as specific dosimeters of copper(II). Figure 2 shows the absorption spectra in MeCN of the three macrocycles 2, 3 and 4.

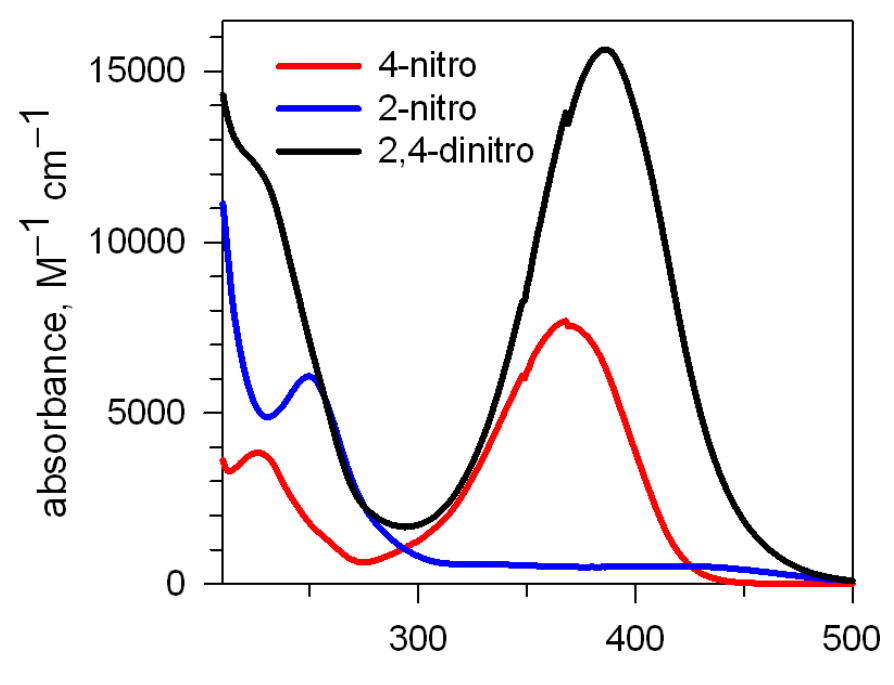

wavelength, $\mathrm{nm}$

Figure 1. Absorption spectra of macrocycles 2 (4-nitro in the legend), 3 (2-nitro) and 4 (2,4-dinitro) taken in $\mathrm{MeCN}$ solution, at $25^{\circ} \mathrm{C}$.

Macrocycles 2 (nitrophenyl substituent in para-, yellow-orange color)) and 4 (nitrophenyl substituents in ortho- and para-, orange) show an intense absorption band at $365 \mathrm{~nm}\left(\varepsilon=7950 \mathrm{M}^{-1}\right.$ $\left.\mathrm{cm}^{-1}\right)$ and at $382 \mathrm{~nm}\left(\varepsilon=15900 \mathrm{M}^{-1} \mathrm{~cm}^{-1}\right)$, respectively, which can be ascribed to the CT transition illustrated in Scheme 1. Such a band is absent for the macrocycle 3, which does not bear a nitrophenyl substituent in 4 and shows a pale yellow color.

Macrocycles 2 and 4, in MeCN solution, uptake one $\mathrm{Cu}^{\mathrm{II}}$ ion to give a substitutionally inert complex, from which the metal ion cannot be extruded even under drastic conditions (addition of excess of competing ligands, of strong acid). Figure 2 a shows the spectra taken over the course of the titration of an $\mathrm{MeCN}$ solution of $\mathbf{4}$ with $\mathrm{Cu}^{\mathrm{II}}$. Complexation induces a substantial blue-shift of the absorption band assigned to the CT transition from the anilino group to the 4-nitro substituent (from $385 \mathrm{~nm}$ to $280 \mathrm{~nm}$ ), a behavior previously observed also in the case of derivative 2 (blue-shift from $365 \mathrm{~nm}$ to $260 \mathrm{~nm}$, in $\mathrm{MeCN}))^{1}$ 


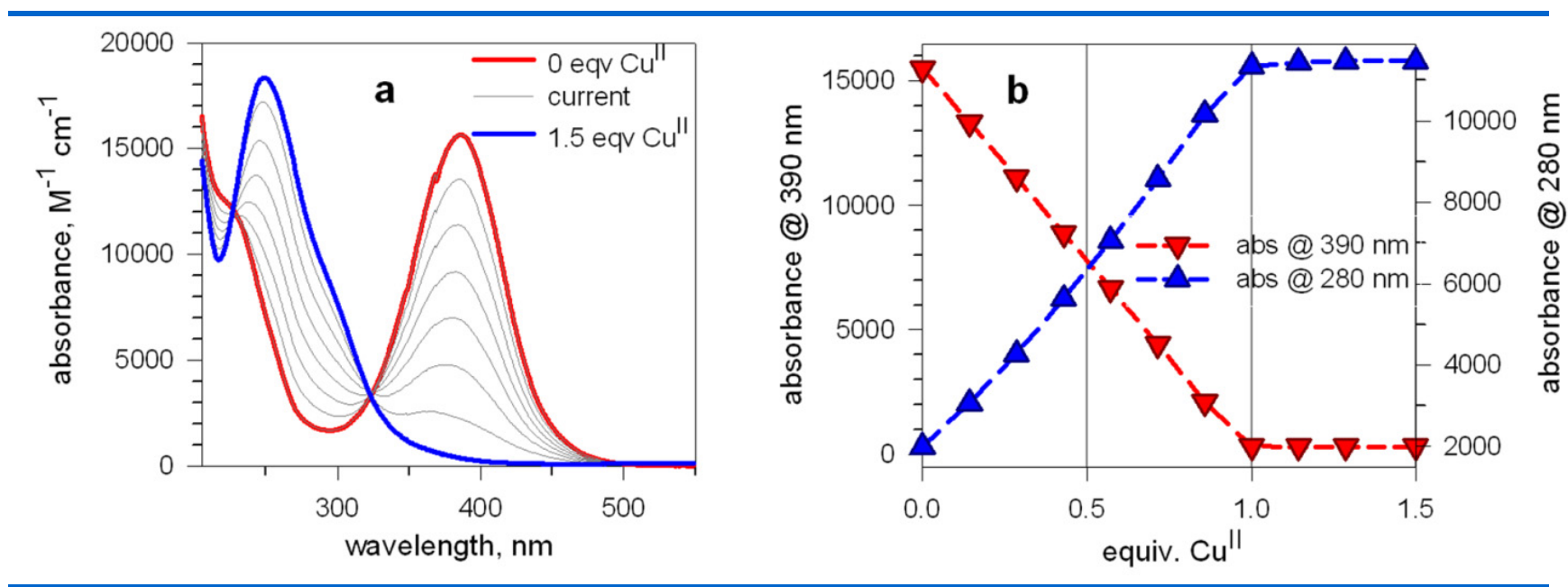

Figure 2. (a) Family of spectra taken over the course of the titration of an MeCN solution of 4 with a standard MeCN solution of $\mathrm{Cu}^{\mathrm{II}}\left(\mathrm{CF}_{3} \mathrm{SO}_{3}\right)_{2}$; (b) titration profiles (absorbance vs. equiv. of $\mathrm{Cu}^{\mathrm{II}}$ ) at $390 \mathrm{~nm}$ and $280 \mathrm{~nm}$ ), indicating the formation of a complex of 1:1 stoichiometry.

The nature of the blue-shift is illustrated in Figure 3, where the 4-nitrophenyl derivative is specifically considered. It is suggested that the excited state of the $\mathrm{Cu}^{\mathrm{II}}$ complex is highly destabilized due to the formal electrostatic repulsion between the metal ion and the anilino nitrogen atom, made positive by the charge transfer (see Fig. 3b). This makes h $v_{\mathrm{CT}}$ distinctly larger than observed for the uncomplexed macrocycle (Fig. 3a ).

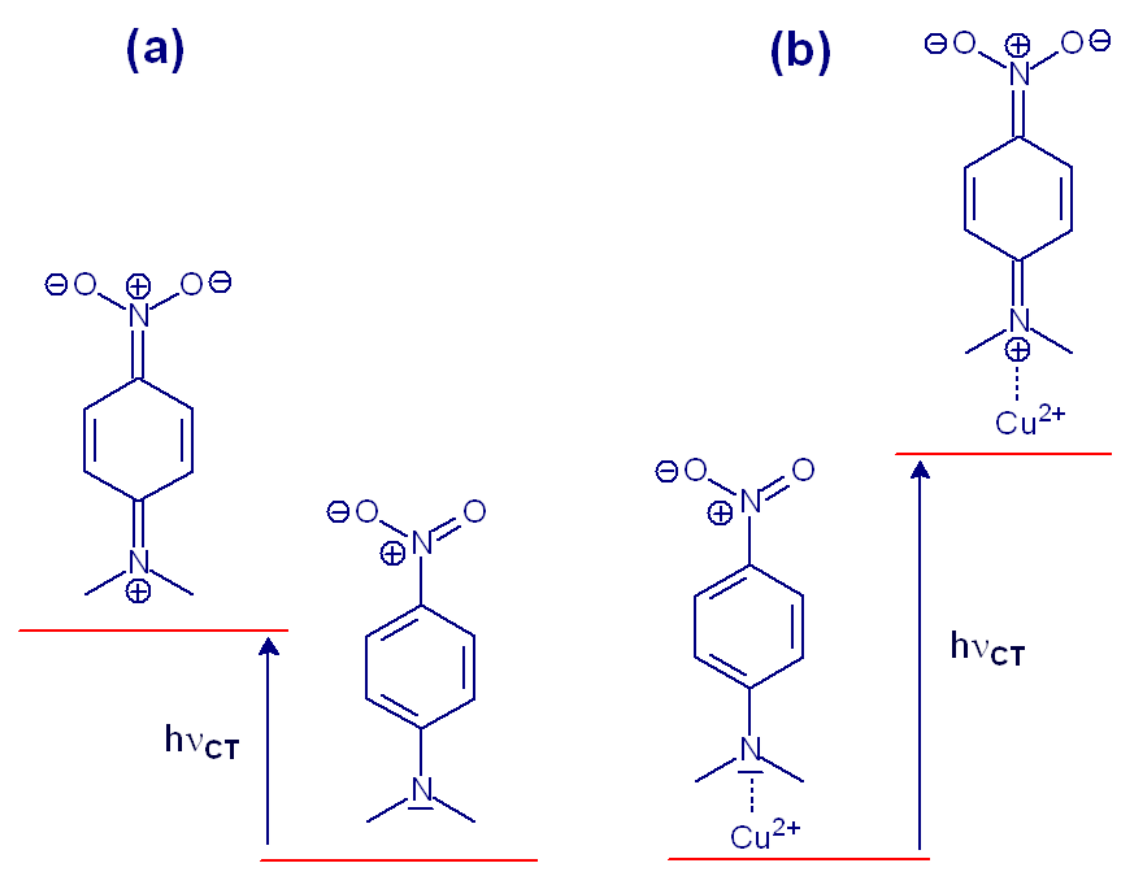

Figure 3. Energy diagrams illustrating the charge transfer transitions in (a) the uncomplexed macrocycle 2, and (b) macrocycle 2 incorporating $\mathrm{Cu}^{\mathrm{II}}$.

Titration profiles at selected wavelengths, shown in Figure $2 b$, indicate the 1:1 stoichiometry of the complex formed in $\mathrm{MeCN}$. Addition of any other divalent $3 \mathrm{~d}$ metal to an $\mathrm{MeCN}$ solution of 4 did not cause any spectral modification. Thus, receptor $\mathbf{4}$ appears as a specific dosimeter for $\mathrm{Cu}^{\mathrm{II}}$, in the same way as the mono-nitro derivative $\mathbf{2}$, but displaying a higher sensitivity due to the higher intensity of the absorption band. The substantial blue-shift makes the yellow diluted solution of the 
macrocycle $\left(<10^{-4} \mathrm{M}\right)$ turn colorless. A yellow to red color change is observed at a higher concentration $\left(\geq 10^{-3} \mathrm{M}\right)$, due to the significant appearance of $d$ - $d$ bands (vide infra).

Complexation of $\mathrm{Cu}^{\mathrm{II}}$ by the 2-nitro derivative $\mathbf{3}$ in $\mathrm{MeCN}$ causes a distinctly different behavior. Figure 4a shows the family of spectra taken over the course of the titration of a $\mathrm{MeCN}$ solution of 4 with a standard $\mathrm{MeCN}$ solution of $\mathrm{Cu}^{\mathrm{II}}\left(\mathrm{CF}_{3} \mathrm{SO}_{3}\right)_{2}$.
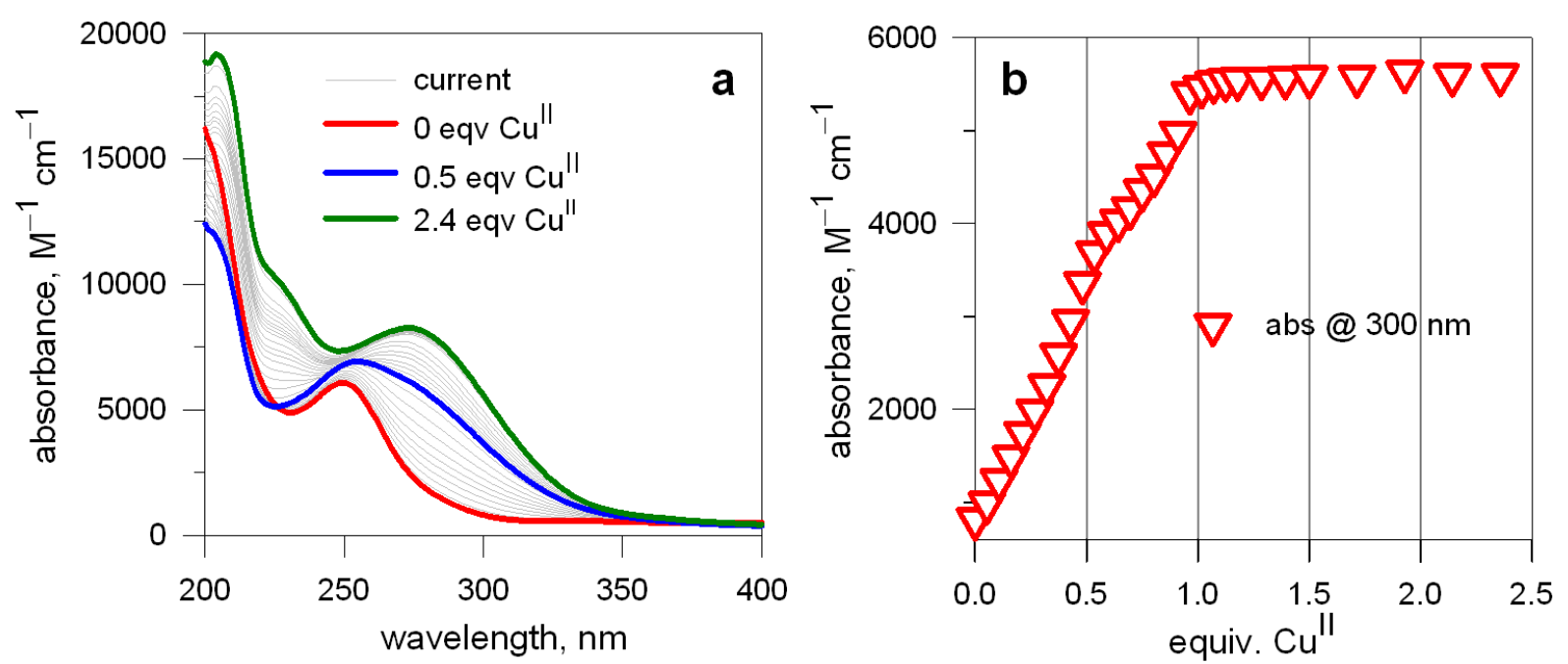

Figure 4. (a) Family of spectra taken over the course of the titration of an MeCN solution of 2 with a standard $\mathrm{MeCN}$ solution of $\mathrm{Cu}^{\mathrm{II}}\left(\mathrm{CF}_{3} \mathrm{SO}_{3}\right)_{2}$; (b) titration profiles (absorbance vs. equiv. of $\mathrm{Cu}^{\mathrm{II}}$ ) at $300 \mathrm{~nm}$ ), which monitors the formation of the 1:1 metal complex..

It is observed that metal complexation provokes a moderate, still distinct red shift of the band ed at $250 \mathrm{~nm}$ (shifted to $275 \mathrm{~nm}$ on addition of excess $\mathrm{Cu}^{\mathrm{II}}$ ). The nature of the red-shift is tentatively illustrated in Figure 5.
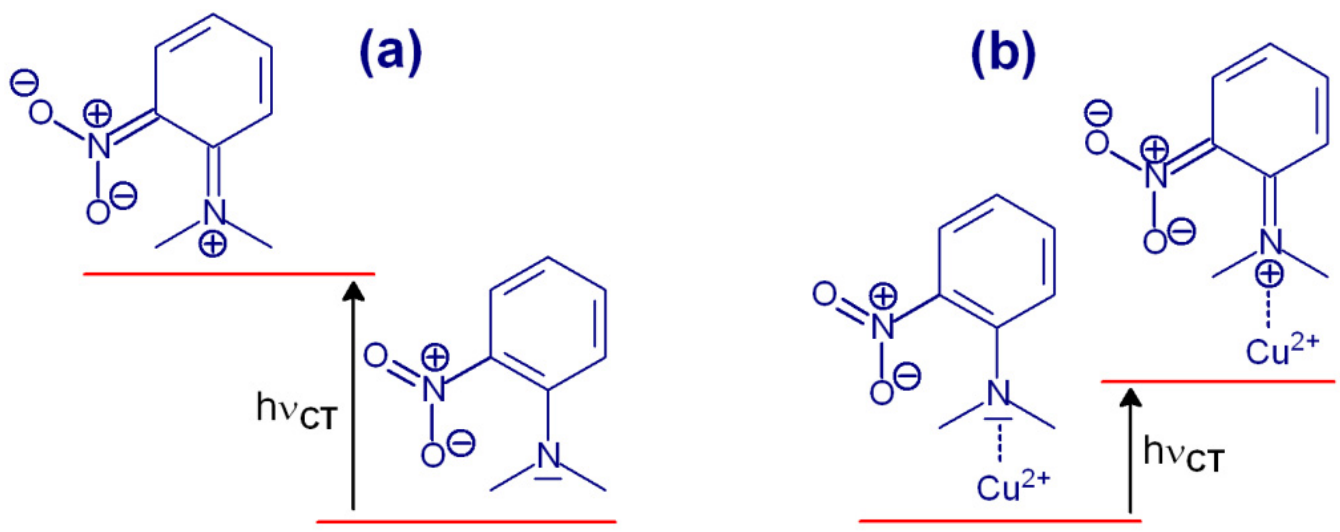

Figure 5. Energy diagrams illustrating the charge transfer transitions in (a) the uncomplexed macrocycle 3, and (b) macrocycle 3 incorporating $\mathrm{Cu}^{\mathrm{II}}$.

In particular, the excited state of the metal complex (part b of the Figure) may be stabilized by the attractive electrostatic interaction between one negatively charged oxygen atom of the nitronate group on one side and (i) the close iminium group, and (ii) the $\mathrm{Cu}^{2+}$ ion, on the other.These interactions cannot be established when the nitro substituent is in ortho- position.

The titration profile shown in Figure $4 \mathrm{~b}$ clearly indicates the incorporation of copper(II) ion by the macrocycle according to a 1:1 stoichiometry. Also in the present case, metal uptake is 
irreversible, thus defining $\mathbf{3}$ as an optical dosimeter of $\mathrm{Cu}^{\mathrm{II}}$. It should be noted that in the titration profile at $300 \mathrm{~nm}$ in Fig. $5 \mathrm{~b}$ a discontinuity exists at the addition of 0.5 equiv. of $\mathrm{Cu}^{\mathrm{II}}$. Such a feature could be tentatively ascribed to the formation of an intermediate species of 1:2 metal/ligand ratio, in which each macrocycle molecule contributes to the coordination with 2 (or 3 ) primary nitrogen atoms.

Conformational aspects: the existence of a scorpionate effect. On preparation of crystalline metal complexes salts of macrocycles $\mathbf{3}$ and $\mathbf{4}$ products of different color were obtained depending upon the chosen experimental conditions. The structural features of the different complex salts were clearly defined through single crystal X-ray diffraction studies.

Complexes of 4. On addition of an $\mathrm{MeOH}$ solution of copper(II) perchlorate (pale blue) to an $\mathrm{MeOH}$ solution of $\mathbf{4}$ (yellow) a red precipitate formed, while the supernatant solution took a violet color. Red crystals suitable for X-ray diffraction studies were obtained on diffusion of diethylether vapor on an $\mathrm{MeCN}$ solution of the red solid. The crystal and molecolar structure of the $\left[\mathrm{Cu}^{\mathrm{II}}(4)\right]\left(\mathrm{ClO}_{4}\right)_{2}$ complex salt is shown in Figure 6.



Figure 6. The crystal and molecular structure of the complex salt trans- $I-\left[\mathrm{Cu}{ }^{\mathrm{II}}(4)\right]\left(\mathrm{ClO}_{4}\right)_{2}$, red color. Hydrogen atoms and counteranions, not involved in metal coordination, have been omitted for clarity.

The complex is five-coordinate, according to a square pyramidal geometry: the four amine nitrogen atoms of the macrocycle occupy the corners of the square, while an oxygen atom of the nitro group in ortho position of the phenyl substituent occupy the apical site. The cyclam framework exhibits a trans- $I$ configuration. The presence of a tertiary nitrogen atom in the cyclam framework induces some distortion in the coordination polyhedron: (i) the $\mathrm{Cu}^{\mathrm{II}}-\mathrm{N}_{\text {tert }}$ distance is 214(1) pm vs the 199(1)-200(1) pm Cu${ }^{\text {II }}-\mathrm{NH}$ distances (while the $\mathrm{Cu}^{\mathrm{II}}-\mathrm{O}$ distance is 233(1) pm), (ii) the $\mathrm{O}-\mathrm{Cu}^{\mathrm{II}}-\mathrm{N}_{\text {tert }}$ angle is $80.7(1)^{\circ}$. 




Figure 7. Red line: spectrum of an $\mathrm{MeCN}$ solution of the red form of the $\left[\mathrm{Cu}^{\mathrm{II}}(4)\right]\left(\mathrm{ClO}_{4}\right)_{2}$ complex salt (trans-I configuration); violet line: spectrum of the same solution taken after several weeks.

On dissolution of the red complex salt trans-I- $\left[\mathrm{Cu}^{\mathrm{II}}(4)\right]\left(\mathrm{ClO}_{4}\right)_{2}$ in $\mathrm{MeCN}$, a red solution is obtained, whose absorption spectrum is shown in Figure 7 (red solid line). The red solution turns violet over a period of weeks. The spectrum of the solution, taken when no further modifications were observed, is shown in Figure 7 (violet solid line). On slow evaporation of the violet solution, the violet complex salt $\mathrm{Cu}^{\mathrm{II}}(4)\left(\mathrm{ClO}_{4}\right)_{2} \cdot \mathrm{MeCN}$ was obtained in a crystalline form, whose molecular structure was determined through X-ray diffraction studies. The corresponding structure is shown in Figure 8 .

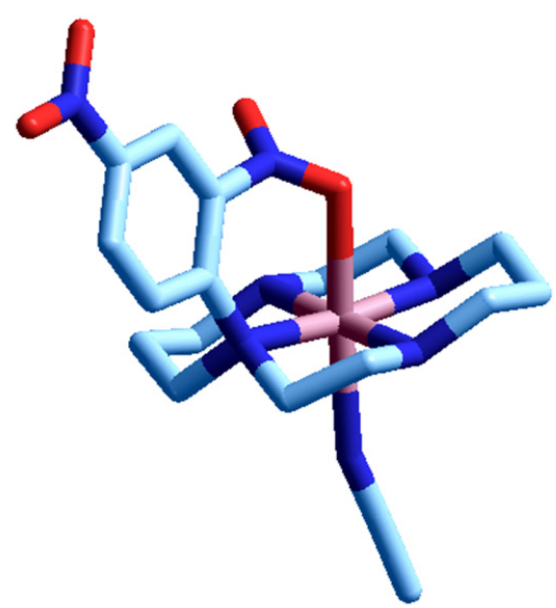

Figure 8. The crystal and molecular structure of the complex salt trans-III- $\left[\mathrm{Cu}{ }^{\mathrm{II}}(4)\left(\mathrm{ClO}_{4}\right)_{2} \cdot \mathrm{MeCN}\right]$, violet color. Hydrogen atoms and counteranions, not involved in metal coordination, have been omitted for clarity.

The complex shows an elongated octahedral geometry, with a scorpion type coordination of the nitro group in the pheyl ortho position and the nitrogen atom of an $\mathrm{MeCN}$ molecule occupying the opposite axial position. Noticeably, the cyclam framework exhibits a trans-III configuration. Also in the present case, the $\mathrm{N} 4$ square is distorted, as the $\mathrm{Cu}^{\mathrm{II}}-\mathrm{N}_{\text {tert }}$ distance $(215(1) \mathrm{pm})$ is distinctly higher than the $\mathrm{Cu}^{\mathrm{II}}-\mathrm{NH}$ distances (ranging from 201(1) to 203(1) pm)). The two axial distances are 241(1) and 240(1) pm for $\mathrm{Cu}^{\mathrm{II}}-\mathrm{O}$ and $\mathrm{Cu}^{\mathrm{II}}-\mathrm{N}$, respectively.

If diethylether vapor is allowed to diffuse on an $\mathrm{MeCN}$ solution of the red complex salt $\left[\mathrm{Cu}^{\mathrm{II}}(4)\right]\left(\mathrm{ClO}_{4}\right)_{2}$, in the presence of $\left[\mathrm{Bu}_{4} \mathrm{~N}\right] \mathrm{Cl}$, blue-violet crystals of the salt $\mathrm{Cu}^{\mathrm{II}}(4) \mathrm{Cl}_{2} \cdot \mathrm{H}_{2} \mathrm{O} \cdot 1 / 2 \mathrm{Et}_{2} \mathrm{O}$ 
form, which were investigated through X-ray diffraction studies. The corresponding crystal and molecular structure is shown in Figure 9.



Figure 9. The crystal and molecular structure of the complex salt trans-III- $\left[\mathrm{Cu}{ }^{\mathrm{II}}(4) \mathrm{Cl}\right] \mathrm{Cl} \cdot \mathrm{H}_{2} \mathrm{O} \cdot 1 / 2\left(\mathrm{C}_{2} \mathrm{H}_{5}\right)_{2} \mathrm{O}$. The chloride counterion, not involved in coordination, as well as solvational molecules have been omitted for clarity.

It is observed that the complex cation $\left[\mathrm{Cu}^{\mathrm{II}}(\mathbf{4}) \mathrm{Cl}\right]^{+}$shows a square pyramidal coordination geometry, with the chloride ion occupying the apical position. The nitro group in ortho position is well far away from the metal, while the macrocycle adopts the trans-III configuration.
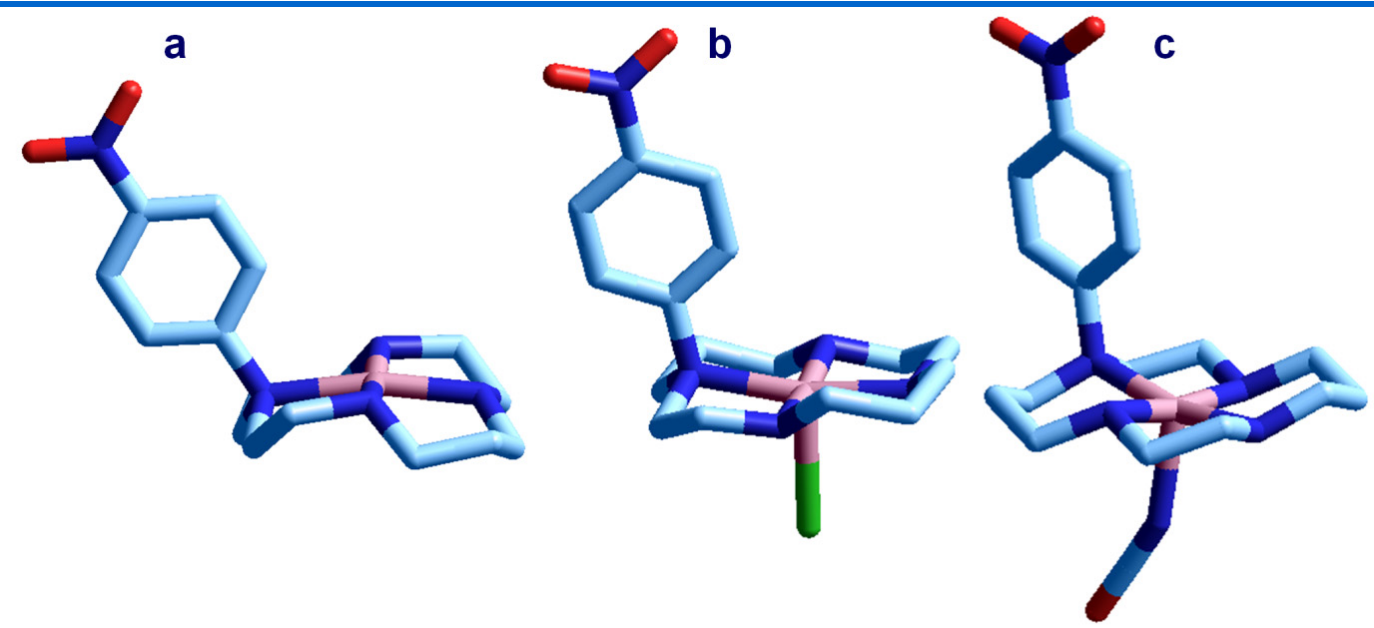

Figure 10. Crystal and molecular structure of the complex salts: (a): trans- $I-\left[\mathrm{Cu}^{\mathrm{II}}(\mathbf{2})\right]\left(\mathrm{ClO}_{4}\right)_{2}$, red color; ${ }^{1}$ (b) 2 (trans-III- $\left.\left[\mathrm{Cu}^{\mathrm{II}}(\mathbf{2}) \mathrm{Cl}\right] \mathrm{Cl}\right) \cdot \mathrm{MeCN} \cdot 5 /{ }_{2} \mathrm{H}_{2} \mathrm{O}$, blue color; (c) trans-III-[Cu $\left.{ }^{\mathrm{II}}(\mathbf{2})(\mathrm{NCO})\right] \mathrm{NCO} \cdot 2\left(\mathrm{H}_{2} \mathrm{O}\right)$, blue color. Hydrogen atoms, counterions and solvational molecules have been omitted for clarity. Crystal of $\mathbf{b}$ contains two similar but not symmetrically equivalent $\left[\mathrm{Cu}^{\mathrm{II}}(\mathbf{2}) \mathrm{Cl}\right]^{+}$molecular cations

We have now observed that on diffusion of diethylether on an $\mathrm{MeCN}$ solution of trans-I-[Cu $\left.{ }^{\mathrm{II}}(2)\right]\left(\mathrm{ClO}_{4}\right)_{2}$ in the presence of an excess of $\left.\left[\mathrm{Bu}_{4} \mathrm{~N}\right]\right] \mathrm{X}(\mathrm{X}=\mathrm{Cl}, \mathrm{NCO})$, the following complex salts can be obtained in a crystalline form, suitable for X-ray diffraction studies: trans-III$\left[\mathrm{Cu}^{\mathrm{II}}(\mathbf{2}) \mathrm{Cl}\right] \mathrm{Cl}$ (Figure 10b) and trans-III-[Cu$\left.{ }^{\mathrm{II}}(\mathbf{2})(\mathrm{NCO})\right] \mathrm{NCO} \cdot \mathrm{H}_{2} \mathrm{O}$ (Figure 10c). For comparative purposes, Figure 10a shows the crystal and molecular structures of the complex salts of the parent macrocycle 2: trans-I-[Cu $\left.{ }^{\mathrm{II}}(2)\right]\left(\mathrm{ClO}_{4}\right)_{2}$ (Figure 10a). ${ }^{1}$ It should be noticed that, in the presence of a coordinating anion like $\mathrm{Cl}^{-}$and $\mathrm{NCO}^{-}$, the complex moves from the square geometry (a) to a square 
pyramidal arrangement $(\mathbf{b}, \mathbf{c})$, while cyclam configuration changes from trans-I to trans-III. In the three complexes, the $\mathrm{Cu}^{\mathrm{II}}-\mathrm{N}_{\text {tert }}$ distances remain a bit longer than the $\mathrm{Cu}^{\mathrm{II}}-\mathrm{NH}$ distances. However, the distortions for the N4 squares in the three complexes of $\mathbf{2}$ are less pronounced than in complex a. Actually, the $\mathrm{Cu}^{\mathrm{II}}-\mathrm{N}_{\text {tert }}$ distances range from 207(1) pm in the trans-I complex (a) to 209(1) pm in the trans-III complex (c), whereas the $\mathrm{Cu}^{\mathrm{II}}-\mathrm{NH}$ distances are in the range 200(1)-204(1) pm. The axial distances are 253(1) and 257(1) pm for $\mathrm{Cu}^{\mathrm{II}}-\mathrm{Cl}$ in the two independent molecules of $\mathbf{b}$ and 218(1) pm for $\mathrm{Cu}^{\mathrm{II}}-\mathrm{N}_{\mathrm{NCO}}$ in complex c. Notice that on halide/pseudohalide coordination the $\mathrm{Cu}^{\mathrm{II}}$ ion, only 3(1) pm over the mean N4 plane in the trans-I complex a, is raised by $18(1) / 23(1) \mathrm{pm}$ from the plane towards the anion, respectively.

On the basis of the structural data described above, the following conclusions can be drawn:

1. The presence of the hindering phenyl substituent favors the trans-I configuration.

2. Coordination of a further ligand (an anion, an $\mathrm{MeCN}$ molecule, the oxygen atom of the nitro group) favors the conversion to the trans-III configuration: the higher the coordinating tendencies of the exotic ligand, the easier the trans-I to trans-III conversion.

Thus, whatever the position the nitro group is, whether ortho- or para-, the kinetically less complicated pathway leads to the formation of a complex in a trans-I configuration. In the case of the complex of macrocycle 4, the five-cordinate scorpionate complex forms. However, this is not the thermodynamically stable species and the trans- $I$ scorpionate species (red) slowly converts in $\mathrm{MeCN}$ to the octahedral scorpionate trans-III form (violet), with an MeCN molecule occupying the axial position opposite to the coordinated oxygen atom of the nitro group. If a coordinating anion is present $\left(\mathrm{Cl}^{-}, \mathrm{NCO}^{-}\right)$, the trans-III complex prefers to bind the anion according to a square pyramidal geometry, diverting the $-\mathrm{NO}_{2}$ oxygen from the axial site and releasing the bound $\mathrm{MeCN}$ molecule to the solution. The metal profits at most from the anion coordination by raising itself 19(1) pm from the N4 plane (a behavior observed also with complexes of 2 with chloride and cyanate).

Complexes of 3. Red solvate complex salt $\left[\mathrm{Cu}^{\mathrm{II}}(3)\right]\left(\mathrm{ClO}_{4}\right)_{2} \cdot \mathrm{MeCN}$ and violet complex salt $[\mathrm{Cu}(3)]\left(\mathrm{ClO}_{4}\right)_{2}$ were obtained through reaction of $\mathrm{Cu}\left(\mathrm{ClO}_{4}\right)_{2}$ with 3 in $\mathrm{MeCN}$ in the same crop. Trans-I and trans-III complex were separated by elution through a cation exchange column. The crystal and molecular structures of the two forms are shown in Figure 11.
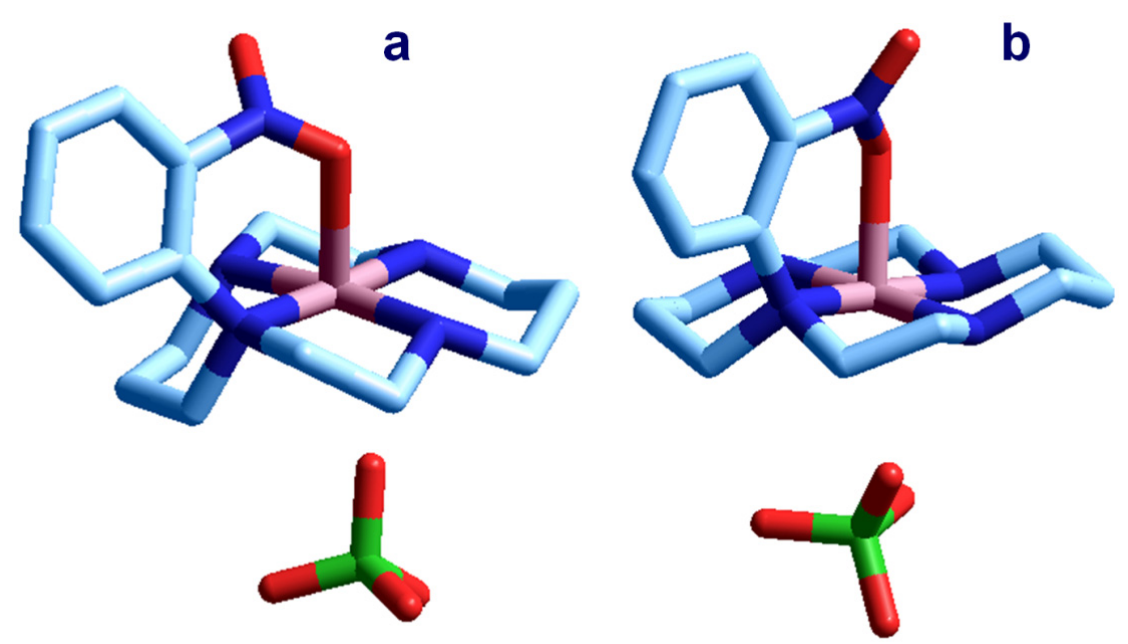

Figure 11. Crystal and molecular structure of the complex salts: (a) : trans- $I-\left[\mathrm{Cu}^{\mathrm{II}}(\mathbf{3})\right]\left(\mathrm{ClO}_{4}\right)_{2} \cdot \mathrm{MeCN}$, red color; and (b) trans-III-[Cu $\left.{ }^{\mathrm{II}}(3)\right]\left(\mathrm{ClO}_{4}\right)_{2}$, violet color. Hydrogen atoms unbound perchlorate ions and solvational molecules have been omitted for clarity. 
As noted for 4, the red form corresponds to the trans-I configuration of the cyclam macrocycle, while the violet complex shows the trans-III arrangement. In contrast to what observed for the analogous complexes of $\mathbf{4}$, crystals of the red trans- $I-\left[\mathrm{Cu}^{\mathrm{II}}(\mathbf{3})\right]^{2+}$ complex contain an $\mathrm{MeCN}$ molecule, which is not bonded to the metal, whereas the violet trans-III $\left[\mathrm{Cu}^{\mathrm{II}}(3)\right]^{2+}$ species does not keep in the solid state any $\mathrm{MeCN}$ molecule. In particular, the apical site opposite to the coordinated nitro group of both trans-I and trans-III $\mathrm{Cu}^{\mathrm{II}}$ complexes of $\mathbf{3}$ is occupied by a perchlorate anion, whose loosely bound oxygen atom is positioned at $277(1)$ pm for trans- $I\left[\mathrm{Cu}^{\mathrm{II}}(3)\right]^{2+}$ species and 272(1) pm for trans-III $\left[\mathrm{Cu}^{\mathrm{II}}(\mathbf{3})\right]^{2+}$ species.

Other structural features are in full agreement with the principles outlined in the previous Section. In particular, both trans-I and trans-III complexes of 3 show $\mathrm{Cu}^{\mathrm{II}}-\mathrm{N}_{\text {tert }}$ distances $(210(1)$ and 209(1) pm) longer than the $\mathrm{Cu}^{\mathrm{II}}-\mathrm{NH}$ distances (in the range 199(1)-203(1) pm). The axial $\mathrm{Cu}^{\mathrm{II}}-\mathrm{O}$ distances are $236(1) \mathrm{pm}$ and $224(1) \mathrm{pm}$ in trans-I $\left[\mathrm{Cu}^{\mathrm{II}}(\mathbf{3})\right]^{2+}$ and trans-III $\left[\mathrm{Cu}^{\mathrm{II}}(\mathbf{3})\right]^{2+}$ complexes, respectively.

Mechanism of the trans-I to trans-III conversion. It has been mentioned that the trans-I complex of both 3 and $\mathbf{4}$ macrocycles slowly and spontaneously converts in solution to the thermodynamically stable trans-III complex, which keeps a scorpionate arrangement. Figure 7 has shown that the two configurational isomers exhibit well distinct spectral features in the $d$ - $d$ region of the absorption spectrum, which allows their detection in solution. Thus, the kinetic aspects of the trans-I to trans-III conversion could be investigated spectrophotometrically.
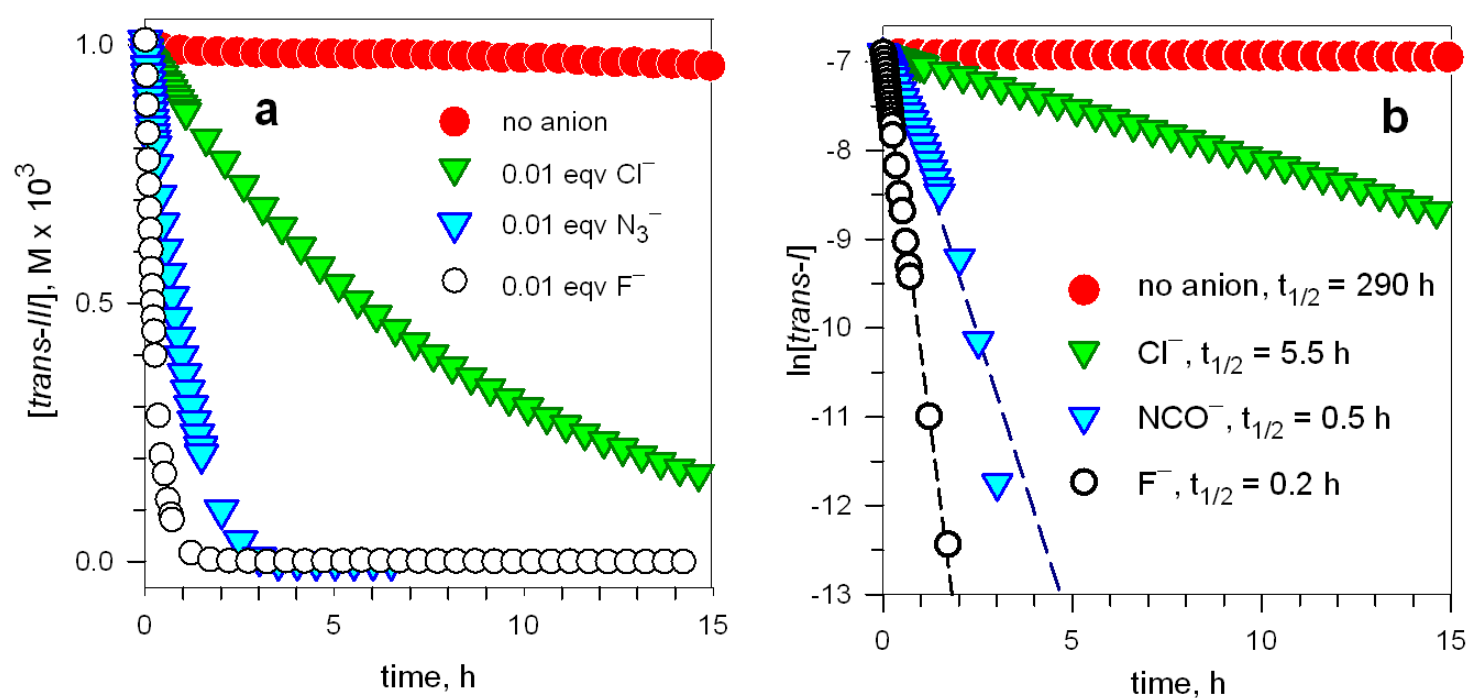

Figure 12. Kinetic studies on the trans-I to trans-III conversion of the trans- $I\left[\mathrm{Cu}^{\mathrm{II}}(\mathbf{3})\right]\left(\mathrm{ClO}_{4}\right)_{2}$ complex in an $\mathrm{MeCN}$ solution at $25^{\circ} \mathrm{C}\left(10^{-3} \mathrm{M}\right)$. The decay of the trans-I complex concentration is monitored through the decrease of the absorbance of the absorption band at $460 \mathrm{~nm}$ : (a) conversion in the absence of anions and in the presence of a catalytic amount of a $\left[\mathrm{Bu}_{4} \mathrm{~N}\right] \mathrm{X}$ salt $\left(10^{-5} \mathrm{M}, \mathrm{X}^{-}=\mathrm{Cl}^{-}, \mathrm{NCO}^{-}, \mathrm{F}^{-}\right)$; (b) $\ln [$ trans- $]$ vs. time plots, disclosing a first-order behavior.

Figure 12a shows the decay of the concentration of the trans-I complex (red filled circles), which has been calculated from the absorbance at $460 \mathrm{~nm}$, corrected for the absorbance of the trans-III complex, of an MeCN solution $10^{-3} \mathrm{M}$ in the trans-I $\left[\mathrm{Cu}^{\mathrm{II}}(4)\right]\left(\mathrm{ClO}_{4}\right)_{2}$ complex salt (red color, values at larger times not reported in the diagram). In Figure $12 \mathrm{~b}, \ln [$ trans- $I]$ has been plotted vs. time (h). The linear behaviour indicates the first-order nature of the process, to which a half-time $t_{1 / 2}$ $\sim 12$ days corresponds. 
The presence of anions in catalytic amounts (i.e. $10^{-5} \mathrm{M}$ ) makes the trans-I-to-trans-III conversion considerably faster. In this connection, Figure 12a shows the decay of the absorbance at $460 \mathrm{~nm}$ for an $\mathrm{MeCN}$ solution $10^{-3} \mathrm{M}$ in $\left[\mathrm{Cu}^{\mathrm{II}}(4)\right]^{2+}$ and $10^{-5} \mathrm{M}$ in $\left[\mathrm{Bu}_{4} \mathrm{~N}\right] \mathrm{Cl}$. The linear $\ln \left[\right.$ trans-III] vs. $\mathrm{t}(\mathrm{h})$ in Figure $12 \mathrm{~b}$ discloses a $t_{1 / 2}=5.5 \mathrm{~h}$. We can tentatively suggest that the trans-I to trans-III conversion may take place through a dissociative mechanism (detachment of an amine nitrogen atom, as a preliminary step to the configurational reorganization). The chloride ion is assumed to temporarily occupy the empty coordination site, thus decreasing the energy of the transition state. Accordingly, anions of higher coordinating tendencies than chloride should make the conversion process faster. Indeed, in the presence of 1/100 equiv. of cyanate, which follows chloride in the spectrochemical series, the rate the configurational rearrangement increases distinctly and the half-time is substantially reduced $\left(t_{1 / 2}=0.5 \mathrm{~h}\right)$.

It is therefore surprising that the highest acceleration is exerted by the less cordinating halide ion, fluoride (see empty circles in Figure 12a), to which a half-time $t_{1 / 2}=13$ minutes corresponds (from the linear plot in Figure $12 \mathrm{~b}$.Such an unexpected behavior has to be related to the Brønsted base properties rather than to the coordinating properties of $\mathrm{F}^{-}$, as it will be discussed in detail in the next Section.

Base effect on the trans-I-to-trans-III conversion. An aqueous solution of the trans-I$\left[\mathrm{Cu}^{\mathrm{II}}(4)\right]\left(\mathrm{ClO}_{4}\right)_{2}$ complex salt, to which excess strong acid had been added and which had been made $0.1 \mathrm{M}$ in $\mathrm{NaClO}_{4}$, was titrated with a standard solution of $\mathrm{NaOH}$, at $25^{\circ} \mathrm{C}$. Figure $13 \mathrm{a}$ shows the family of spectra taken during the course of the titration over the 7.0-12.5 $\mathrm{pH}$ interval.
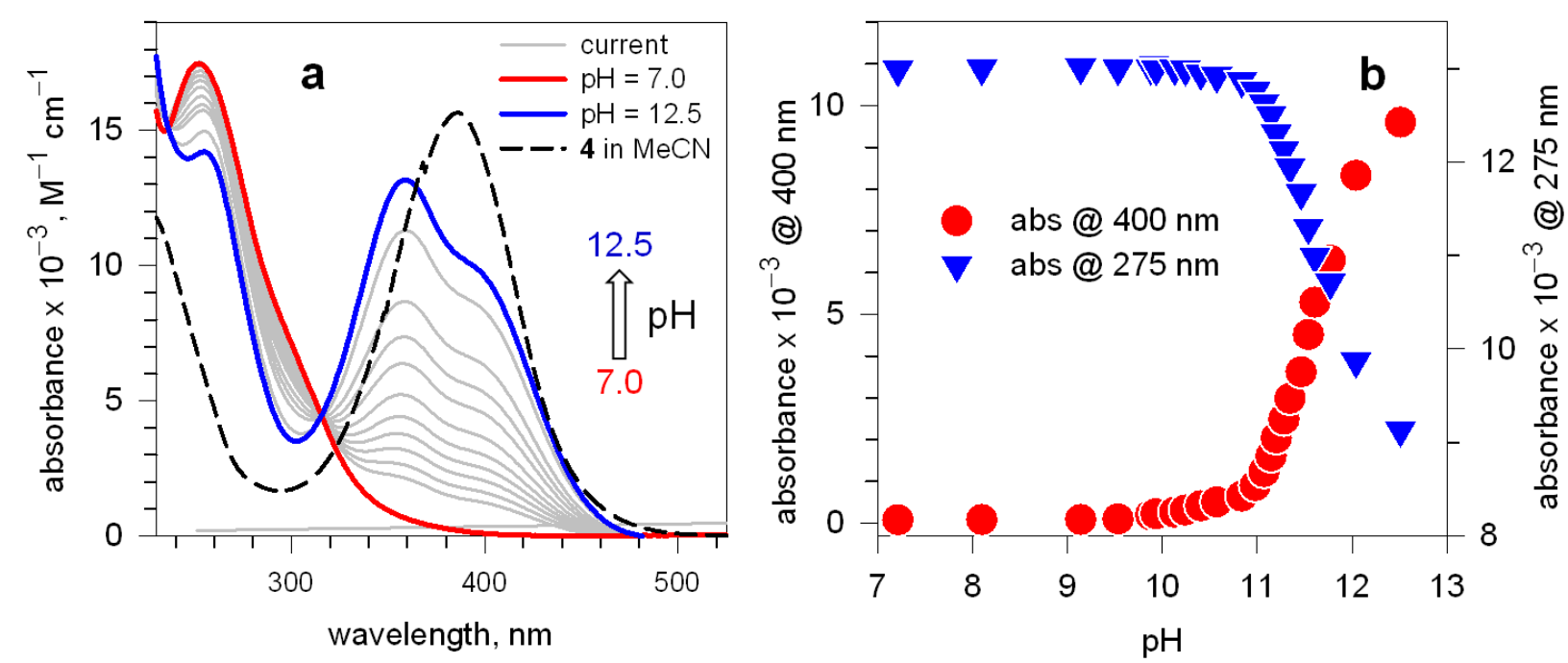

Figure 13. (a) Spectra taken over the course of the titration of an aqueous solution $10^{-4} \mathrm{M}$ in trans- $I$ $\left[\mathrm{Cu}^{\mathrm{II}}(4)\right]\left(\mathrm{ClO}_{4}\right)_{2}$ and $0.1 \mathrm{M}_{\text {in }} \mathrm{NaClO}_{4}$; (b) titration profiles based on the decreasing absorbance at $275 \mathrm{~nm}$, monitoring the concentration of the $\left[\mathrm{Cu}^{\mathrm{II}}(4)\right]^{2+}$ complex (blue triangles, right vertical axis) and the increasing absorbance at $400 \mathrm{~nm}$, due to the demetalated-deprotonated macrocyle 4 (red circles, left vertical axis).

It is observed that at $\mathrm{pH} \geq 10$ the absorbance of the band at $275 \mathrm{~nm}$, pertinent to the $\left[\mathrm{Cu}^{\mathrm{II}}(4)\right]^{2+}$ complex, decreases according to a sigmoidal profile. At the same $\mathrm{pH}$ a new band develops, ed at $360 \mathrm{~nm}$, with a well defined shoulder at $400 \mathrm{~nm}$, still showing a sigmoidal profile. It is hypothesized that $\left[\mathrm{Cu}^{\mathrm{II}}(4)\right]^{2+}\left(=\left[\mathrm{Cu}^{\mathrm{II}}(\mathrm{HL})\right]^{2+}\right)$, behaves as a monoprotic acid, according to the equilibrium (1), which involves simultaneous demetalation:

$$
\left[\mathrm{Cu}^{\mathrm{II}}(\mathrm{HL})\right]^{2+}+\mathrm{OH}^{-} \leftrightarrows \mathrm{L}^{-}+\mathrm{Cu}^{2+}+\mathrm{H}_{2} \mathrm{O}
$$


From the two intersecting curves in Figure $13 \mathrm{~b}$ a value of $\mathrm{p} K_{\mathrm{a}} \sim 11.8$ can be roughly estimated. Thus, the band ed at $360 \mathrm{~nm}$ with a shoulder at $400 \mathrm{~nm}$ should pertain to the deprotonated macrocycle $\mathrm{L}^{-}(\mathrm{HL}=4)$ In Figure $13 \mathrm{a}$, the spectrum of the metal-free macrocycle $4(\mathrm{HL})$ in $\mathrm{MeCN}$ is also displayed for comparative purposes (dotted black line), which originates from one single transition. The fact that the absorption at a $\mathrm{pH} \geq 10$ results from two distinct transitions suggests that the $\mathrm{L}^{-}$form exists as an equilibrium mixture of two species, probably differing for the position of the deprotonated amine group, whether closer or farther from the phenylamine nitrogen atom. To the two isomeric species, dipoles of different intensity correspond, as well as transitions of different energy.

The occurrence of demetalation in a strongly basic solution was demonstrated by the following experiment: an aqueous solution of the the trans- $I-\left[\mathrm{Cu}{ }^{\mathrm{II}}(4)\right]\left(\mathrm{ClO}_{4}\right)_{2}$ complex salt was brought to $\mathrm{pH}$ $=14$ with $\mathrm{NaOH}$; the yellow solution was then extracted with $\mathrm{CHCl}_{3}$, to which the yellow color was transferred. One drop of the $\mathrm{CHCl}_{3}$ layer was dissolved in $\mathrm{MeOH}$ and the ESI mass of the solution was determined: a peak m/z $367.2\left(\mathrm{M}+\mathrm{H}^{+}, 100 \%\right)$ was observed; no peaks with the typical isotopic pattern of $\mathrm{Cu}^{\mathrm{II}}$ were detected.

Then, we titrated a $10^{-3} \mathrm{M}$ solution of the trans- $I-\left[\mathrm{Cu}^{\mathrm{II}}(4)\right]\left(\mathrm{ClO}_{4}\right)_{2}$ complex salt in $\mathrm{MeCN}$ with a solution of $\left[\mathrm{Bu}_{4} \mathrm{~N}\right] \mathrm{F}$ in $\mathrm{MeCN}$. The recorded family of spectra is shown in Figure $14 \mathrm{a}$.
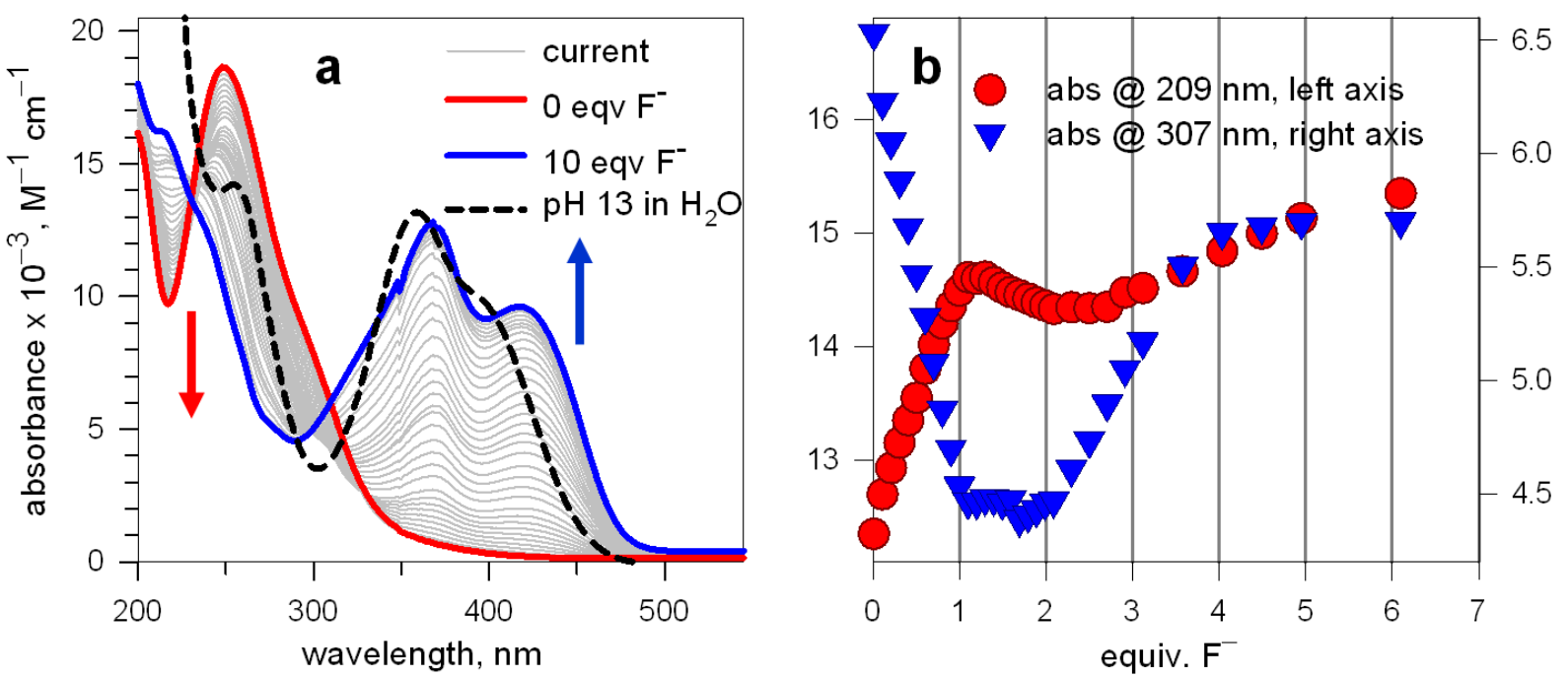

Figure 14. (a) Family of spectra recorded over the course of the titration of a $10^{-4} \mathrm{M}$ solution of the trans- $I$ $\left[\mathrm{Cu}^{\mathrm{II}}(4)\right]\left(\mathrm{ClO}_{4}\right)_{2}$ complex salt in $\mathrm{MeCN}$ with a solution of $\left[\mathrm{Bu}_{4} \mathrm{~N}\right] \mathrm{F}$ in $\mathrm{MeCN}$ (optical path $1 \mathrm{~cm}$ ); (b) titration profiles at selected wavelengths, illustrating the occurrence of a two-step process, at 1 and 2 equiv. of added fluoride.

It is observed that on fluoride addition the band ed at $250 \mathrm{~nm}$, corresponding to the copper(II) complex, decreases in intensity, while a new two-transition band develops at 350-450 nm. Such a band reaches a limiting intensity on addition of excess of fluoride and its shape is strongly reminiscent of that observed in a strongly basic aqueous solution and pertaining to the deprotonated macrocycle $\mathrm{L}^{-}$(reported as a black dotted line in Figure 14a for comparative purposes). In particular, the band in the visible region shows two well distinct transitions at 360 and $430 \mathrm{~nm}$. Thus, the $\mathrm{F}^{-}$ion in the $\mathrm{MeCN}$ solution acts as a strong base, taking one proton from an $\mathrm{N}-\mathrm{H}$ group of the macrocycle and inducing demetalation. However, the stoichiometry of the process is not straightforward. In particular, titration profiles at different wavelengths (e.g. at 209 and $307 \mathrm{~nm}$, see Figure 14b) indicate discontinuity after the addition of 1 equiv. and of 2 equiv. of $\mathrm{F}^{-}$, suggesting the 
occurence of a two-step process. In particular, it is proposed that in the 1st step the fluoride ion coordinates the metal to give a five-coordinate complex, analogous to the $\left[\mathrm{Cu}^{\mathrm{II}}(4) \mathrm{Cl}\right]^{+}$species, whose structure is illustrated in Figure 9. In the 2nd step, deprotonation of one $\mathrm{N}-\mathrm{H}$ fragment of the macrocycle takes place with formation of the $\mathrm{HF}_{2}{ }^{-}$hydrogen bonding complex and demetalation. The two equilibria are described below:

$$
\begin{gathered}
{\left[\mathrm{Cu}^{\mathrm{II}}(\mathrm{HL})\right]^{2+}+\mathrm{F}^{-} \leftrightarrows\left[\mathrm{Cu}^{\mathrm{II}}(\mathrm{HL}) \mathrm{F}\right]^{+}} \\
{\left[\mathrm{Cu}^{\mathrm{II}}(\mathrm{HL}) \mathrm{F}\right]^{+}+\mathrm{F}^{-} \leftrightarrows \mathrm{Cu}^{2+}+\mathrm{L}^{-}+\mathrm{HF}_{2}^{-}}
\end{gathered}
$$

In fact, if one $\mathrm{F}^{-}$ion in an aprotic solvent is not an especially strong base, two $\mathrm{F}^{-}$ions exert a strongly basic behavior due to the formation of the hydrogen bonding complex $\mathrm{HF}_{2}{ }^{-}$, for which the highest HB energy in the gas phase has been determined $\left(38.6 \mathrm{kcal} \mathrm{mol}^{-1}\right){ }^{6}$ Fluoride induced deprotonation of an acidic $\mathrm{N}-\mathrm{H}$ fragment had been previously observed in the case of urea derivatives $(\mathrm{BH}),{ }^{7-10}$ when investigated as anion receptors, according to the two stepwise equilibria reported below:

$$
\begin{gathered}
\mathrm{BH}+\mathrm{F}^{-} \leftrightarrows[\mathrm{BH} \cdots \mathrm{F}]^{-} \\
{[\mathrm{BH} \cdots \mathrm{F}]+\mathrm{F}^{-} \leftrightarrows \mathrm{B}^{-}+\mathrm{HF}_{2}{ }^{-}}
\end{gathered}
$$

First, the hydrogen bonding complex $\left[\mathrm{BH}^{\cdots} \mathrm{F}\right]^{-}$forms, eq. (4), then, on addition of the second fluoride ion, deprotonation of one $\mathrm{N}-\mathrm{H}$ urea fragment takes place, according to an equilibrium displaced to the right by the formation of $\mathrm{HF}_{2}{ }^{-}$, eq. (5). ${ }^{11}$

This may explain the strong acceleration of the trans-I-to-trans-III conversion induced by a catalytic amount of fluoride (see Figure 12). In fact, it may happen that traces of fluoride provoke deprotonation of a microscopic amount of the complex, inducing demetalation, conformational rearrangement, new protonation and new metal complexation. At this stage, the fluoride ion can begin a new cycle.

The spectrophotometric titration experiment illustrated in Figure 14, carried out in a cuvette of $1 \mathrm{~cm}$ optical pathway, was also carried out in a cuvette of $10 \mathrm{~cm}$ optical path in order to detect spectral changes in the visible region and monitor the occurrence of $d$ - $d$ transitions.
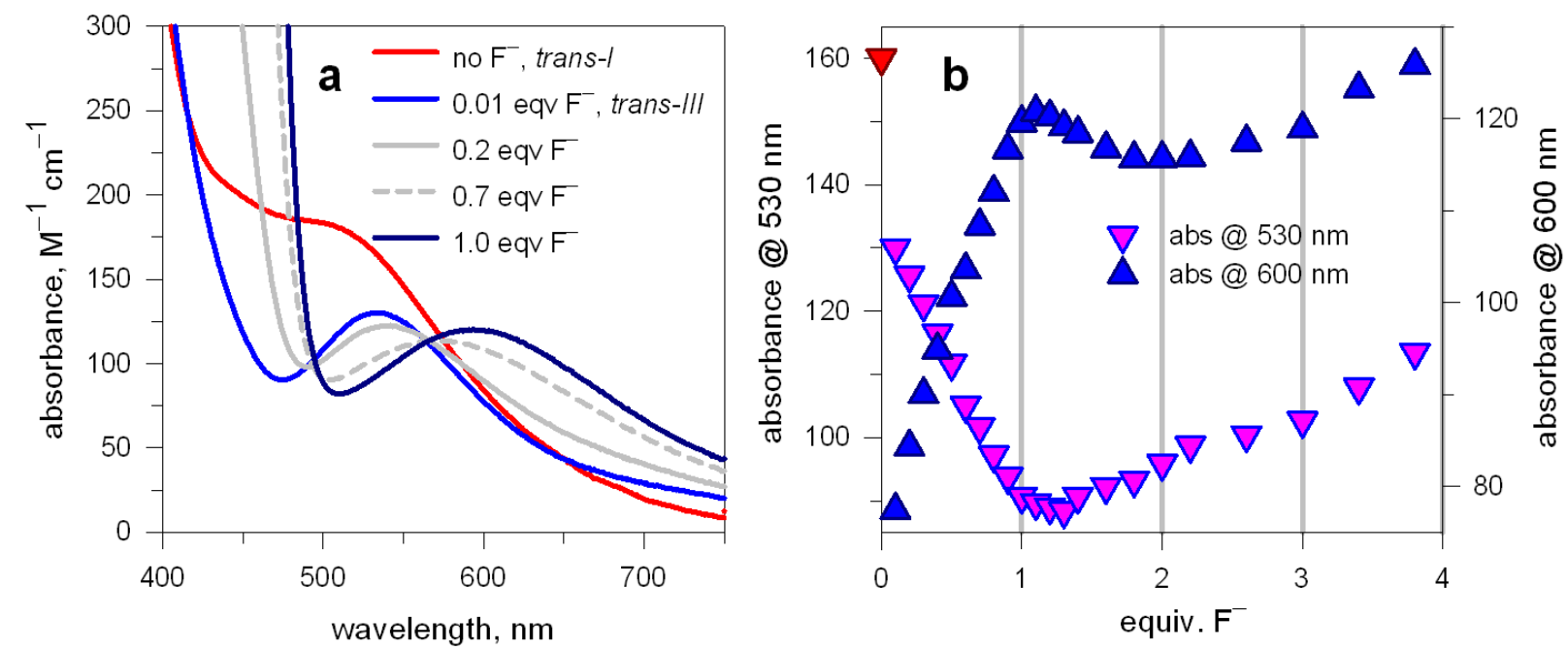

Figure 15. (a) Spectra recorded over the course of the titration of a $10^{-4} \mathrm{M}$ solution of the trans-I$\left[\mathrm{Cu}^{\mathrm{II}}(4)\right]\left(\mathrm{ClO}_{4}\right)_{2}$ complex salt in $\mathrm{MeCN}$ with a solution of $\left[\mathrm{Bu}_{4} \mathrm{~N}\right] \mathrm{F}$ in $\mathrm{MeCN}$ (optical path $10 \mathrm{~cm}$ ); addition of 0.01 equiv. of $\mathrm{F}^{-}$to the red solution favors the quick formation of the trans-III complex and the solution 
turns violet; (b) titration profiles at selected wavelengths; the red triangle on the left vertical axis pertains to the trans-I complex prior the addition of $\mathrm{F}^{-}$.

The red dotted line in Figure 15a indicates the spectrum of the solution before anion addition and corresponds to the red trans-I-[Cu$\left.{ }^{\mathrm{II}}(\mathrm{HL})\right]^{2+}$ complex. On addition of 0.1 equiv. of $\mathrm{F}^{-}$, a substantial spectral change quickly takes place and the spectrum indicated by the pink line forms: this is the spectrum of the trans-III-[Cu$\left.{ }^{\mathrm{II}}(\mathrm{HL})\right]^{2+}$ complex, whose formation has been made fast by the presence of 0.1 equiv. of fluoride. Further substoichiometric additions of $\mathrm{F}^{-}$induced a steady redshift of the $d-d$ band, as typically observed on axial coordination of an additional ligand to a copper(II)-tetramine square complex. The process can be followed through the absorbance profiles shown in Figure 15b. The decrease of the absorbance at $530 \mathrm{~nm}$ corresponds to the disappearance of the trans-III- $\left[\mathrm{Cu}^{\mathrm{II}}(\mathrm{HL})\right]^{2+}$ scorpionate complex, while the increase at $600 \mathrm{~nm}$ is related to the formation of the trans-III-[Cu$\left.{ }^{\mathrm{II}}(\mathrm{HL}) \mathrm{F}\right]^{+}$species of presumably square-pyramidal geometry. However, after the addition of 1 equiv. of anion, a neat discontinuity of the two profiles is observed, due to the incipient decomposition of the macrocyclic complex. A completely similar behavior has been observed with the corresponding non-scorpionate complex of macrocycle $\mathbf{2}$ (see Supplementary Information).

\section{- CONCLUSION}

It has been shown that appending of a nitrophenyl substituent at a nitrogen atom seriously modifies the spectral properties of cyclam and of its copper(II) complexes. In particular, nitrophenylcyclam derivatives 2 and 4, containing a nitro group in para- position, in an $\mathrm{MeCN}$ solution incorporate $\mathrm{Cu}^{\mathrm{II}}$ according to an irreversible process signaled by a neat color change (yellow-to-red), associated to a significant blue-shift of the charge transfer band. For macrocycle 3, whose nitro substituent is positioned in ortho-, copper(II) incorporation results in a red-shift response. In any case, all the investigated nitrophenylcyclam derivatives accumulate the dose and should be considered colorimetric dosimeters. They are specific for copper(II) as they do not complex any other metal ion under the same conditions, at room temperature.

When in the ortho- position of the phenyl substituent (macrocycles 3 and 4), the nitro group can apically coordinate the $\mathrm{Cu}^{\mathrm{II}}$ ion, according to a scorpionate mode. Nitro coordination influences the configuration of the cyclam-like macrocycle. In fact, the $\left[\mathrm{Cu}^{\mathrm{II}}(2)\right]^{2+}$ complex (one nitro group in para-, scorpionate coordination prevented) is obtained in the trans- $I$ form, a configuration which is indefinitely maintained. The trans-III form is obtained only in the presence of stoichiometric amount of coordinating anions (e.g. $\mathrm{Cl}^{-}$), with formation of a square-pyramidal complex. The $\mathrm{Cu}^{\mathrm{II}}$ complex of 4 (one nitro group in ortho-) is obtained as a perchlorate salts a scorpionate in a trans-I configuration, which slowly converts to the trans-III arrangement, maintaining the apical coordination of the nitro fragment. The conversion is dramatically accelerated by catalytic amounts of $\mathrm{Cl}^{-}, \mathrm{NCO}^{-}$and $\mathrm{F}^{-}$. While for $\mathrm{Cl}^{-}$and $\mathrm{NCO}^{-}$the effect can be associated to the capability of the anion to stabilize through coordination any dissociative intermediate, the very powerful effect exerted by $\mathrm{F}^{-}$seems to be related to the deprotonation of one $\mathrm{N}-\mathrm{H}$ fragment of the macrocycle, driven by the formation of the highly stable $\mathrm{HF}_{2}^{-}$complex ion.

This work was undertaken in order to design specific and irreversible receptors for $\mathrm{Cu}^{\mathrm{II}}$, by coupling the high coordinating tendencies of cyclam and the unique chromophoric properties of the nitrophenyl substituent. While the synthesized ligands display the aimed analytical properties, novel features of interest in basic inorganic and coordination chemistry were discovered, which include 
the binding capability of the nitro group according to a scorpionate mode, the factors affecting the thermodynamic and kinetic relative stability of the trans-I and trans-III configurations of complexed cyclam, the role exerted by the fluoride ion in the deprotonation of a coordinated $\mathrm{N}-\mathrm{H}$ fragment.

\section{EXPERIMENTAL SECTION}

Physical measurements. UV/Vis spectra were recorded on a Varian CARY 100 spectrophotometer with quartz cuvettes of the appropriate path lenght $(0.1$ or $1 \mathrm{~cm})$. In any case, the concentration of the chromophore and the optical path were adjusted in order to obtain spectra with $\mathrm{AU} \leq 1$. Mass spectra were acquired on a Thermo-Finnigan ion trap LCQ Advantage Max instrument, equipped with an ESI source.

Syntheses. All the macrocycles have been prepared through a multistep synthesis involving a reaction of triprotected cyclam, 1,4,8-tris(tert-butoxycarbonyl)-1,4,8,11-tetraazacyclotetradecane $\left(\mathrm{BOC}_{3} \text { cyclam }\right)^{1}$, with the appropriate nitroaryl fluoride, followed by deprotection of the intermediate to yield the desired product. The mono-nitro derivatives 2 (4-nitrophenyl) and 3 (2nitrophenyl) have been synthesized according to literature procedure, ${ }^{1, R E F}$ with some modifications, whereas the dinitro derivative 4 (2,4-dinitrophenyl) has been obtained under milder conditions.

\section{1,4,8-Tris(tert-butoxycarbonyl)-11-(4-nitrophenyl)-1,4,8,11-tetraazacyclotetradecane}

(5). A solution of tri-Boc cyclam $(2.5 \mathrm{~g}$., $5 \mathrm{mmol})$ in anhydrous DMSO $(30 \mathrm{~mL})$ was added of cesium carbonate (6 g., $18.42 \mathrm{mmol}$ ) and heated under stirring to $100{ }^{\circ} \mathrm{C}$ under a dinitrogen atmosphere; 1-fluoro-4-nitrobenzene $(1.06 \mathrm{~mL}, 10 \mathrm{mmol})$ was then added dropwise and the resulting suspension was left to react for 24 hours, added of an additional amount of cesium carbonate (3 g., $9.12 \mathrm{mmol})$ and 1-fluoro-4-nitrobenzene $(0.53 \mathrm{~mL}, 5 \mathrm{mmol})$ and kept until no more increase in the concentration of the product could be detected by MS-ESI (three days). The reaction mixture was left to cool to room temperature and taken up with ethyl acetate $(100 \mathrm{~mL})$. The organic solution was then washed with a saturated sodium hydrogencarbonate solution $(2 \times 30 \mathrm{~mL})$ and brine $\left(1 \times 30 \mathrm{~mL}\right.$, left overnight on $\mathrm{Na}_{2} \mathrm{SO}_{4}$, filtered and evaporated to give an oil. The latter-one was purified through silica gel chromatography (n-hexane/ ethyl acetate 3:2) to give the desired product as a yellow oil (0.99 g., yield: $31.8 \%)$, which was satisfactorily characterized through mass spectroscopy $\left(\mathrm{ESI}\left(\mathrm{CH}_{3} \mathrm{OH}\right): \mathrm{m} / \mathrm{z} 623,4\left(\mathrm{M}+\mathrm{H}^{+}, 100 \%\right)\right.$ and used as such for the following step.

1-(4-nitrophenyl)-1,4,8,11-tetraaza-cyclotetradecane (2). 5 (0.99 g, $1.6 \mathrm{mmol}$ ) was dissolved in dichloromethane $(17 \mathrm{~mL})$ and trifluoroacetic acid $(1.7 \mathrm{~mL})$ was added dropwise. The solution was stirred at room temperature under a dinitrogen atmosphere until the reaction was complete ( 20 hours, checked by MS-ESI). The solvent was then removed under vacuum to give a dark yellow precipitate, which was dissolved in $5 \mathrm{~mL}$ of ethyl acetate and then precipitated with diethylether $(75 \mathrm{~mL})$. The solid (a trifluoroacetate adduct) was separated through filtration, taken up with dichloromethane $(20 \mathrm{~mL})$ and washed with an equal volume of aqueous $\mathrm{NaOH} 5 \%$. The organic solution was kept overnight on $\mathrm{Na}_{2} \mathrm{SO}_{4}$, filtered, and brought to dryness under vacuum to give the pure macrocycle 2 (0.45 g., yield: 88.24\%). $\mathrm{MS}\left(\mathrm{CH}_{3} \mathrm{OH}, \mathrm{ESI}\right): \mathrm{m} / \mathrm{z} 322,2\left(\mathrm{M}+\mathrm{H}^{+}, 100 \%\right)$.

1-(2-nitrophenyl)-1,4,8,11-tetraaza-cyclotetradecane (3). The synthetic procedure is same as described above for macrocycle 2 , the only difference being the replacement of cesium carbonate with potassium carbonate. Thus, the reaction of tri-Boc cyclam $(2.5 \mathrm{~g}, 5 \mathrm{mmol})$ in anhydrous DMSO $(30 \mathrm{~mL})$ with potassium carbonate $(2.6 \mathrm{~g}$., $18.8 \mathrm{mmoli})$ and 1-fluoro-2-nitrobenzene (1.06 $\mathrm{mL}, 10 \mathrm{mmol}$ ) at $100{ }^{\circ} \mathrm{C}$ for three days (including a further addiction of potassium carbonate, $1.3 \mathrm{~g}$. 
and 1-fluoro-2-nitrobenzene, $0.53 \mathrm{~mL}$ ) followed by workup and chromatographic separation (silica gel, n-hexane/ethyl acetate 3:2, gradient) afforded 1,4,8,11-tris(tert-butoxycarbonyl)-11-(2nitrophenyl)-1,4,8,11-tetraazacyclotetradecane (1.91 g, $3.1 \mathrm{mmol}$, yield: $61.4 \%)$ as an oil, which solidified on standing. Treatment with trifluoroacetic acid $(3.4 \mathrm{~mL})$ in dichloromethane $(33 \mathrm{~mL})$ gave the pure product $(0.8$ g, yield: $81.2 \%)$. $\mathrm{MS}\left(\mathrm{CH}_{3} \mathrm{OH}, \mathrm{ESI}\right): \mathrm{m} / \mathrm{z} 322,2\left(\mathrm{M}+\mathrm{H}^{+}, 100 \%\right)$.

1-(2,4-dinitrophenyl)-1,4,8,11-tetraaza-cyclotetradecane (4). A solution of 1-fluoro-2,4dinitrobenzene $(0.93 \mathrm{~g}, 5 \mathrm{mmol})$ in anhydrous THF $(50 \mathrm{~mL})$ was added dropwise to a boiling solution of 1,4,8-Tris(tert-butoxycarbonyl)-1,4,8,11-tetraazacyclotetradecane $(2.5 \mathrm{~g}, 5 \mathrm{mmol})$ and $N, N$-diisopropylethylamine $(0.86 \mathrm{~mL}, 5 \mathrm{mmol})$ in the same solvent $(150 \mathrm{~mL})$. The solution was refluxed under a dinitrogen atmosphere for 24 hours when an additional amount of reagents $(0.47 \mathrm{~g}$ of 1-fluoro-2,4-dinitrobenzene and $0.43 \mathrm{~mL}$ of $N, N$-diisopropylethylamine) was added, then left to react for additional $20 \mathrm{~h}$. The solvent and the excess of $N, N$-diisopropylethylamine were removed in vacuo and the residue was purified through liquid chromatography (silica gel, ethyl acetate/hexane 1:1, gradient) to give a yellow oil (3 $\mathrm{g}, 4.49 \mathrm{mmol}$, yield: $89.8 \%$ ), which was satisfactorily characterized through mass spectroscopy $\left(\mathrm{ESI}\left(\mathrm{CH}_{3} \mathrm{OH}\right): \mathrm{m} / \mathrm{z} 668,4\left(\mathrm{M}+\mathrm{H}^{+}, 100 \%\right)\right.$. The tri-BOC derivative was then dissolved in dichloromethane $(47 \mathrm{~mL})$, added of trifluoroacetic acid $(4.7 \mathrm{~mL})$ and left to react at room temperature until complete removal of the tert-butoxycarbonyl groups $(\sim$ 27 hours). The volatiles were distilled off under vacuum and the residual orange-yellow oil was dissolved in ethyl acetate $(40 \mathrm{~mL})$; the resulting solution was then treated with diethyl ether $(200$ $\mathrm{mL})$ to form a sticky, yellow solid. The solid was taken up with aqueous $\mathrm{NaOH} 10 \%(50 \mathrm{~mL})$ to give a mixture which was extracted with toluene $(3 \times 50 \mathrm{~mL})$. The combined organic phases were then washed with water $(3 \times 50 \mathrm{~mL})$, dried overnight on $\mathrm{Na}_{2} \mathrm{SO}_{4}$, filtered and distilled to dryness under vacuum to give the pure product $(0.95 \mathrm{~g}$., $2.58 \mathrm{mmol}$, yield: $57.4 \%)\left(\mathrm{ESI}\left(\mathrm{CH}_{3} \mathrm{OH}\right): \mathrm{m} / \mathrm{z}\right.$ $369,4\left(\mathrm{M}+\mathrm{H}^{+}, 100 \%\right)$.

Trans-I-[Cul(4)](ClO $)_{2} \cdot 18.4 \mathrm{mg}$ of $4(0.0501 \mathrm{mmol})$ was dissolved in $3 \mathrm{~mL}$ of $\mathrm{CH}_{2} \mathrm{Cl}_{2}$, to which a solution of $18.2 \mathrm{mg}(0.0491 \mathrm{mmol})$ of $\mathrm{Cu}\left(\mathrm{ClO}_{4}\right)_{2} \cdot 6 \mathrm{H}_{2} \mathrm{O}$ in $0.5 \mathrm{~mL}$ of $\mathrm{MeCN}$ was added at room temperature. A red brown solution formed, to which $5 \mathrm{~mL}$ of diethylether were added. A dark-brown gummy precipitate formed, which was suspended in $1 \mathrm{~mL}$ of $\mathrm{MeOH}$ and sonicated. A red-orange powder formed, which was filtered on a Hirsch funnel, washed with iced $\mathrm{MeOH}$, dried and recrystalized from $\mathrm{MeCN}$ through slow diffusion of diethylether. Red crystals were obtained (21.8 mg, yield 71\%. ESI-MS: m/z $214.5\left(\mathrm{M}^{2+}\right)$.

Trans-III-[Cu"(4)](ClO $)_{2}$. Violet crystals suitable for X-ray diffraction studies were obtained by dissolving the red trans- $I-\left[\mathrm{Cu}^{\mathrm{II}}(4)\right]\left(\mathrm{ClO}_{4}\right)_{2}$ complex salt in $\mathrm{MeCN}\left(\sim 10^{-3} \mathrm{M}\right)$. Then, 0.01 eqv of $\left[\mathrm{Bu}_{4} \mathrm{~N}\right] \mathrm{F}$ was added. The solution was kept at room temperature for $1 \mathrm{~d}$. On slow diffusion of diethylether, violet crystals formed.

Trans-I-[Cu"(3)](ClO $\left.)_{2}\right)_{2}$ and Trans-III-[Cu"(3)]( $\left.\mathrm{ClO}_{4}\right)_{2}$. A similar procedure as for trans-I-[Cu $\left.{ }^{\text {II }}(4)\right]\left(\mathrm{ClO}_{4}\right)_{2}$ was followed. The dark-brown gummy precipitate which formed was charged on a Sephadex SP C-25 column and eluted with aqueuous $\mathrm{NaClO}_{4}$. A red and a violet fraction were separated (the red one eluted first). Slow evaporation at room temperature of the two fractions gave the crystalline materials studied through X-ray diffraction.

Complexes containing chloride and cyanate were obtained through crystallization of $\mathrm{MeCN}$ solutions of the trans- $I$ perchlorate complex salt in the presence of an excess of the corresponding $\left[\mathrm{Bu}_{4} \mathrm{~N}\right] \mathrm{X}$ salt $(\mathrm{X}=\mathrm{Cl}, \mathrm{NCO})$. 
$X$-ray crystallographic studies. Diffraction data for $\left[\mathrm{Cu}^{\mathrm{II}}(4)\right]\left(\mathrm{ClO}_{4}\right)_{2}($ trans $-I$, red color, 0.43 $\left.\times 0.32 \times 0.22 \mathrm{~mm}^{3}\right),\left[\mathrm{Cu}^{\mathrm{II}}(4)\right]\left(\mathrm{ClO}_{4}\right)_{2} \cdot \mathrm{MeCN}$ (trans-III, violet color, $\left.0.51 \times 0.14 \times 0.04 \mathrm{~mm}^{3}\right)$, $\left[\mathrm{Cu}^{\mathrm{II}}(4) \mathrm{Cl}\right] \mathrm{Cl} \cdot \mathrm{H}_{2} \mathrm{O} \cdot{ }^{1} / 2\left(\mathrm{Et}_{2} \mathrm{O}\right)$ (trans-III, blue-violet color, $0.51 \times 0.14 \times 0.04 \mathrm{~mm}^{3}$, with disordered diethylether and partly populated atom sites of water solvent molecules), $\left[\mathrm{Cu}^{\mathrm{II}}(2)(\mathrm{NCO})\right] \mathrm{NCO} \cdot 2\left(\mathrm{H}_{2} \mathrm{O}\right)\left(\right.$ trans-III, blue color, $0.62 \times 0.40 \times 0.11 \mathrm{~mm}^{3}$, with disordered cyanate and partly populated atom sites of water solvent molecules), $\left[\mathrm{Cu}^{\mathrm{II}}(\mathbf{3})\right]\left(\mathrm{ClO}_{4}\right)_{2} \cdot \mathrm{MeCN}($ trans-I, red color, $\left.0.50 \times 0.36 \times 0.11 \mathrm{~mm}^{3}\right)$, and $\left[\mathrm{Cu}^{\mathrm{II}}(3)\right]\left(\mathrm{ClO}_{4}\right)_{2}$ (trans-III, violet color, $0.65 \times 0.43 \times 0.07$ $\mathrm{mm}^{3}$ ) have been collected by means of a conventional Enraf-Nonius CAD4 four circle diffractometer.

Diffraction data for $2\left(\left[\mathrm{Cu}^{\mathrm{II}}(2) \mathrm{Cl}\right] \mathrm{Cl}\right) \cdot \mathrm{MeCN} \cdot{ }^{5} / 2\left(\mathrm{H}_{2} \mathrm{O}\right)$ (trans-III, blue color $0.28 \times 0.12 \times 0.10$ $\mathrm{mm}^{3}$, with a disordered acetonitrile molecule) have been collected by means of a Bruker-Axs CCDbased three circle diffractometer. Both instruments work at ambient temperature with graphitemonochromatized Mo-K $\alpha$ X-radiation $(\lambda=0.71073 \AA)$.

Data reductions for intensities collected with the conventional diffractometer were performed with the WinGX package; ${ }^{12}$ absorption effects were evaluated with the $\psi$-scan method, ${ }^{13}$ and absorption correction was applied to the data. Data reduction for frames collected by the CCDbased system was performed with the SAINT software; ${ }^{14}$ absorption effects were empirically evaluated by the $S A D A B S$ software, ${ }^{15}$ and absorption correction was applied to the data. All crystal structures were solved by direct methods $\left(S I R\right.$ 97) ${ }^{16}$ and refined by full-matrix least-square procedures on $F^{2}$ using all reflections (SHELXL 97). ${ }^{17}$ Anisotropic displacement parameters were refined for all non-hydrogen atoms, excluding some atom sites partly populated and belonging to disordered solvent molecules. Hydrogens bonded to $\mathrm{C}$ atoms were placed at calculated positions with the appropriate AFIX instructions and refined using a riding model; hydrogens bonded to secondary amines of the macrocycle moiety and to water molecules (when possible) were located in the final $\Delta F$ maps and their positions were successively refined restraining the $\mathrm{N}-\mathrm{H}$ or $\mathrm{O}-\mathrm{H}$ distance to be $0.90 \pm 0.01 \AA$. Crystal data are reported in Table 1.

Table 1. Crystal data for investigated crystals.

\begin{tabular}{|c|c|c|c|c|c|c|c|}
\hline & {$\left[\mathrm{Cu}^{\mathrm{II}}(4)\right]\left(\mathrm{ClO}_{4}\right.$} & $\begin{array}{c}\left.\mathrm{u}^{\mathrm{II}}(4)\right]\left(\mathrm{ClO}_{4}\right)_{2} \\
\cdot \mathrm{MeCN}\end{array}$ & $\begin{array}{c}{\left[\mathrm{Cu}^{\mathrm{II}}(\mathbf{4}) \mathrm{Cl}\right] \mathrm{Cl}} \\
\cdot \mathrm{H}_{2} \mathrm{O} \cdot{ }^{1} /{ }_{2}\left(\mathrm{Et}_{2} \mathrm{O}\right)\end{array}$ & $\begin{array}{l}2\left(\left[\mathrm{Cu}^{\mathrm{II}}(\mathbf{2}) \mathrm{Cl}\right] \mathrm{Cl}\right) \\
\cdot \mathrm{MeCN} \cdot{ }^{5} / 2\left(\mathrm{H}_{2} \mathrm{O}\right)\end{array}$ & $\begin{array}{c}{\left[\mathrm{Cu}^{\mathrm{II}}(\mathbf{2})(\mathrm{NCO})\right]} \\
\mathrm{NCO} \cdot 2\left(\mathrm{H}_{2} \mathrm{O}\right)\end{array}$ & $\begin{array}{c}{\left[\mathrm{Cu}^{\mathrm{II}}(\mathbf{3})\right]\left(\mathrm{ClO}_{4}\right)_{2}} \\
\cdot \mathrm{MeCN}\end{array}$ & {$\left[\mathrm{Cu}^{\mathrm{II}}(\mathbf{3})\right]\left(\mathrm{ClO}_{4}\right)_{2}$} \\
\hline Formula & $\begin{array}{c}\mathrm{C}_{16} \mathrm{H}_{26} \mathrm{Cl}_{2} \mathrm{CuN}_{6} \\
\mathrm{O}_{12}\end{array}$ & $\begin{array}{c}\mathrm{C}_{18} \mathrm{H}_{29} \mathrm{Cl}_{2} \mathrm{CuN}_{7} \\
\mathrm{O}_{12}\end{array}$ & $\begin{array}{c}\mathrm{C}_{18} \mathrm{H}_{33} \mathrm{Cl}_{2} \mathrm{CuN}_{6} \\
\mathrm{O}_{5.5}\end{array}$ & $\begin{array}{c}\mathrm{C}_{34} \mathrm{H}_{62} \mathrm{Cl}_{4} \mathrm{Cu}_{2} \mathrm{~N}_{11} \\
\mathrm{O}_{6.5}\end{array}$ & $\mathrm{C}_{18} \mathrm{H}_{31} \mathrm{CuN}_{7} \mathrm{O}_{6}$ & $\begin{array}{c}\mathrm{C}_{18} \mathrm{H}_{30} \mathrm{Cl}_{2} \mathrm{CuN}_{6} \\
\mathrm{O}_{10}\end{array}$ & $\begin{array}{c}\mathrm{C}_{16} \mathrm{H}_{27} \mathrm{Cl}_{2} \mathrm{CuN}_{5} \\
\mathrm{O}_{10}\end{array}$ \\
\hline$M$ & 628.88 & 669.93 & 555.96 & 997.82 & 505.04 & 624.93 & 583.88 \\
\hline Crystal system & monoclinic & triclinic & orthorhombic & monoclinic & triclinic & monoclinic & monoclinic \\
\hline Space group & $P 2_{1} / c$ (no. 14$)$ & $P-1$ (no. 2) & $P b c a$ (no. 61) & $P 2_{1} / n$ (no. 14$)$ & $P-1$ (no. 2 ) & $P 2_{1} / n$ (no. 14$)$ & $P 2_{1} / n($ no. 14$)$ \\
\hline$a[\AA]$ & $10.850(2)$ & $8.034(2)$ & $16.012(2)$ & $15.284(1)$ & $9.094(3)$ & $14.623(3)$ & $7.726(3)$ \\
\hline$b[\AA]$ & $13.510(3)$ & $9.452(2)$ & $8.742(2)$ & $17.598(1)$ & $11.082(2)$ & $12.515(3)$ & $18.477(10)$ \\
\hline$c[\AA]$ & $16.975(8)$ & $18.277(3)$ & $35.516(7)$ & $17.430(1)$ & $12.948(2)$ & $14.864(3)$ & $16.006(8)$ \\
\hline$\alpha\left[^{\circ}\right]$ & 90 & $79.894(12)$ & 90 & 90 & $93.023(25)$ & 90 & 90 \\
\hline$\beta\left[^{\circ}\right]$ & $94.969(12)$ & $83.490(16)$ & 90 & $99.454(1)$ & $109.011(20)$ & $101.631(18)$ & $94.54(2)$ \\
\hline$\gamma\left[{ }^{\circ}\right]$ & 90 & $79.058(17)$ & 90 & 90 & $106.694(32)$ & 90 & 90 \\
\hline$V\left[\AA^{3}\right]$ & $2479.0(14)$ & $1336.9(5)$ & $4971.3(16)$ & $4624.3(3)$ & $1166.25(55)$ & $2664.4(10)$ & 2277.7(19) \\
\hline$Z$ & 4 & 2 & 8 & 4 & 2 & 4 & 4 \\
\hline Unique refl. & 7197 & 4705 & 4362 & 8203 & 4111 & 4669 & 3970 \\
\hline $\begin{array}{l}\text { Strong data } \\
{\left[\mathrm{I}_{O}>2 \sigma\left(\mathrm{I}_{\mathrm{O}}\right)\right]}\end{array}$ & 5184 & 3676 & 3632 & 6533 & 3534 & 3485 & 3330 \\
\hline$R 1, w R 2$ & $0.0754,0.1898$ & $0.0761,0.1605$ & $0.0719 / 0.1474$ & $0.0469 / 0.1277$ & $0.0560 / 0.1281$ & $0.0789 / 0.1924$ & $0.0800 / 0.1939$ \\
\hline
\end{tabular}




\section{ASSOCIATED CONTENT}

\section{Supporting information}

X-ray crystallographic files in CIF format and plots showing thermal ellipsoids for the studied molecular crystals. Details on the spectrophotometric titrations in MeCN.

This material is available free of charge via the Internet at http://pubs.acs.org.

\section{AUTHOR INFORMATION}

\section{Corresponding Author:}

*E-mail: luigi.fabbrizzi@unipv.it

\section{Notes}

The authors declare no competing financial interest.

\section{ACKNOWLEDGEMENTS}

The financial support of the Italian Ministry of University and Research (PRIN-InfoChem) is gratefully acknowledged.

\section{- REFERENCES}

(1) Boiocchi, M.; Fabbrizzi, L.; Maurizio Licchelli, M.; Sacchi, Vázquez-López, M.; Zampa, C. Chem. Commun. 2003, 1812-1813.

(2) Chae, M. Y.; Czarnik, A. W. J. Am. Chem. Soc. 1992, 114, 9704-9705.

(3) Lindoy, L. F. The Chemistry of Macrocyclic Ligand Complexes, Cambridge University Press, Cambridge, UK, 1989.

(4) Barefield, E. K. Coord. Chem. Rev. 2010, 254, 1607-1627.

(5) Boiocchi,M.; Fabbrizzi, L.; Foti,F.; Monzani,E.; Poggi, A. Org. Lett. 2005, 7, 3417-3420.

(6) (a) Larson. J. W.; McMahon, T. B. Inorg. Chem. 1984, 23, 2029; (b) Gronert, S. J. Am. Chem. Soc. 1993, 115, 10258-10266.

(7) Boiocchi, M.; Del Boca, L.; Gómez-Esteban, D.; Fabbrizzi, L.; Licchelli, M.; Monzani, E. J. Am. Chem. Soc. 2004, 126, 16507-16514.

(8) Boiocchi, M.; Del Boca, L.; Gómez-Esteban, D.; Fabbrizzi, L.; Licchelli, M.; Monzani, E. Chem. Eur. J. 2005, 11, 3097-3104.

(9) Gómez-Esteban, D.; Fabbrizzi, L.; Licchelli, M.; Monzani, E. Org. Biomol. Chem. 2005, 3, 1495-1500.

(10) Gómez-Esteban, D.; Fabbrizzi, L.; Licchelli, M. J. Org. Chem. 2005, 70, 5717-5720.

(11) Amendola, V.; Fabbrizzi, L.; Gómez, D. E.; Licchelli, M. Acc. Chem. Res. 2006, 39, 343353.

(12) Farrugia, L. J. J. Appl. Crystallogr. 1999, 32, 837-838.

(13) North, A. C. T.; Phillips, D. C.; Mathews, F. S. Acta. Crystallogr. 1968, A24, 351-359. 
(14) SAINT Software Reference Manual, Version 6, Bruker AXS Inc.: Madison, WI, USA, 2003.

(15) Sheldrick, G. M.: SADABS Siemens Area Detector Absorption Correction Program, University of Göttingen: Göttingen, Germany, 1996.

(16) Altomare, A.; Burla, M. C.; Camalli, M.; Cascarano, G. L.; Giacovazzo, C.; Guagliardi, A.; Moliterni, A. G. G.; Polidori, G.; Spagna, R. J. Appl. Crystallogr. 1999, 32, 115-119.

(17) Sheldrick, G. M. Acta Crystallogr. 2008, A64, 112-122. 


\section{For Table of Contents Only}

Macrocycles containing a nitrophenyl substituent directly linked to a nitrogen atom incorporate irreversibly a copper(II) ion with substantial change of absorption spectra in the UV and visible regions, thus behaving as optical dosimeters. When in the ortho position of the phenyl substituent, the nitro group coordinates the $\mathrm{Cu}^{\mathrm{II}}$ center according to a scorpionate mode, while the complex moves from a trans-I to a trans-III configuration. On anion coordination (e.g. chloride), the nitro group detaches.

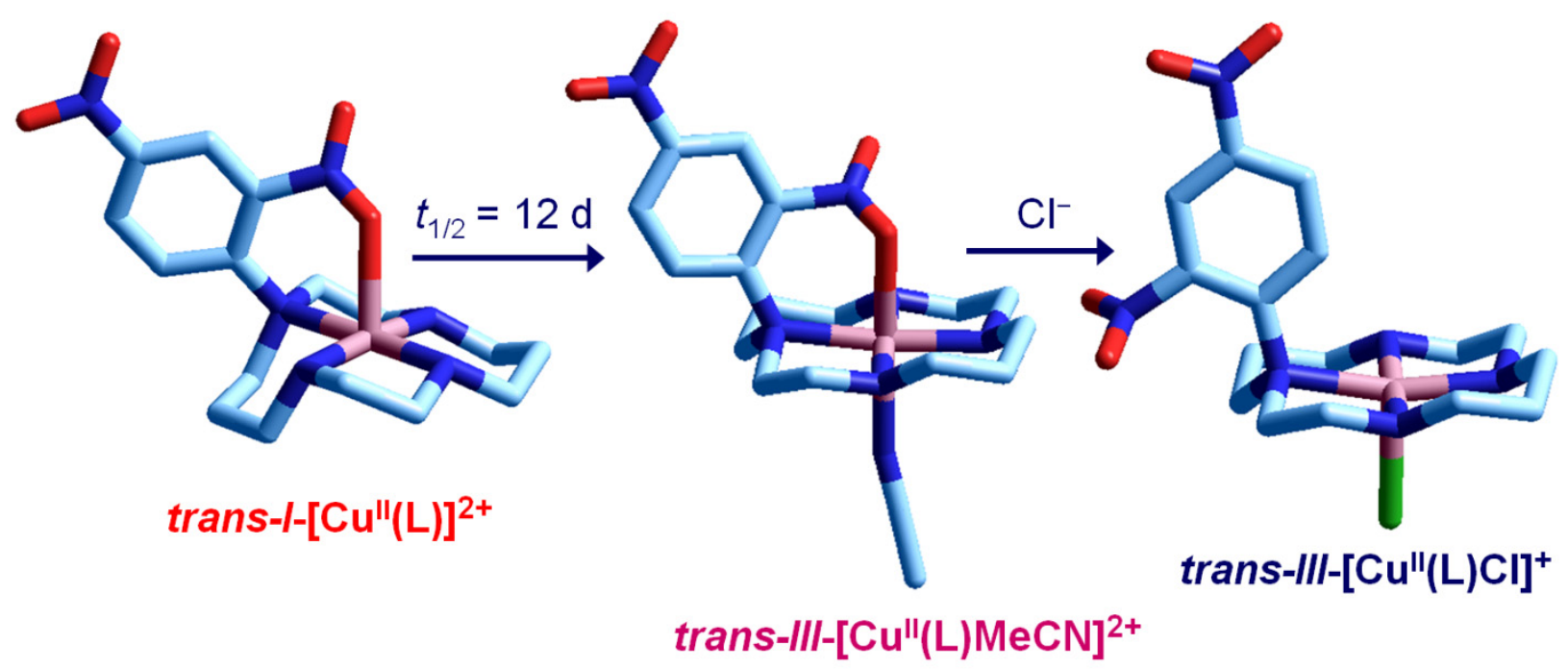

